\title{
Nature, wavefield properties and source mechanism of volcanic tremor: a review
}

\author{
Konstantinos I. Konstantinou*, Vera Schlindwein ${ }^{1}$ \\ Department of Geological Sciences, University of Durham, Science Laboratories, South Road DH1 3LE, UK
}

Received 25 October 2000; accepted 5 April 2002

\begin{abstract}
Volcanic tremor has attracted considerable attention by seismologists because of its potential value as a tool for forecasting eruptions and better understanding the physical processes that occur inside active volcanoes. However, unlike tectonic earthquakes where the dominant source process is brittle failure of rock, the driving mechanism of tremor seems to involve complex interactions of magmatic fluids with the surrounding bedrock. These interactions are responsible for the following distinct characteristics found in volcanic tremor recorded at many volcanoes worldwide: (a) the onset of tremor may be emergent or impulsive, with its amplitude showing in many cases a direct relationship to the volcanic activity; (b) in the frequency domain the spectra consist of a series of sharp peaks in the band 0.1-7 $\mathrm{Hz}$, representing either a fundamental frequency and its harmonics, or a random distribution, while quite often they exhibit temporal variations in their content; (c) the depth of the source can vary considerably from one volcano to another in the range of a few hundred metres to $40 \mathrm{~km}$; (d) tremor may occur prior to and/or after eruptions with a duration that ranges from several minutes to several days or months. The methods used to study tremor include spectral analysis using both the Fast Fourier Transform and the Maximum Entropy Method, polarisation analysis of the wavefield and methods that make use of array data to deduce the backazimuth and type of the seismic waves as well as the location of the source. Visual and/or recorded acoustic observations of the ongoing volcanic activity have assisted in many cases to further constrain proposed physical mechanisms for the generation of tremor. The models suggested as possible sources of tremor can be grouped as follows: (a) fluid-flow-induced oscillations of conduits transporting magmatic fluids; (b) excitation and resonance of fluid-filled cracks; (c) bubble growth or collapse due to hydrothermal boiling of groundwater; (d) a variety of models involving the oscillations of magma bodies with different geometries. It has been proposed by many authors that the source of tremor is not unique and may differ from one volcano to another, a fact that adds more difficulty in the source modelling efforts. As data quality, computer power and speed are improving, it may be possible in the near future to decipher and accurately model tremor source processes at different volcanic environments.
\end{abstract}

(C) 2002 Elsevier Science B.V. All rights reserved.

Keywords: active volcanoes; fluid-filled cracks; fluid-flow induced oscillations; hydrothermal boiling; oscillations of magma bodies; volcanic tremor

\footnotetext{
${ }^{1}$ Present address: Federal Institute for Geosciences and Natural Resources, Section B3, Stilleweg 2, 30655 Hannover, Germany

* Corresponding author. Present address: Institute of Earth Sciences, Academia Sinica, P.O. Box 1-55, Nankang Taipei, Taiwan, ROC. Fax: +886-2-27839871

E-mail address: kostas@earth.sinica.edu.tw (K.I. Konstantinou).
} 


\section{Introduction}

Since the beginning of seismic observations near active volcanoes by Omori in 1912, interest in the study of a particular type of seismic signal called volcanic tremor, that occurs prior to and after eruptions, has been growing steadily. The quest for insight into the processes that take place during eruptions, as well as the social benefits stemming from their forecasting in densely populated volcanic areas, are the primary reasons for such a growth (Aki, 1992). However, from a quite early stage seismologists realised that the study of volcanic tremor is far more complicated than the study of signals generated by sources such as shear faulting or man-made explosions.

Trying to analyse and understand the physical mechanism of the source of tremor has proved to be a very difficult task. Complexities arise from the fact that a volcano essentially represents the place of interaction between materials of different physical properties: magmatic fluids, the surrounding bedrock, and exsolved gases when ascending magma reaches shallow depths in the crust. Thus a number of candidate mechanisms or even a combination of them may be generating volcanic tremor. Depending on the eruptive activity of the volcano, and the flow regime and chemical composition of magma, the characteristics of these sources may be expected to change in time and/or space. These factors put constraints on the applicability of proposed mechanisms to individual volcanoes and indicate that there may not be a stationary, unique source even in the same volcano (McNutt, 1986; Yamaoka et al., 1991; Sherburn et al., 1999).

Another point of difficulty is the uncertainty regarding the relationship between tremor and the different kinds of volcanic earthquakes that occur during eruptions. The fact that one class of these earthquakes, known as low-frequency events, has similar waveforms and spectra to volcanic tremor led researchers to believe that tremor may be a superposition of such events (Fehler, 1983). However, that proposition has not resolved the problem of what common source mechanism generates both phenomena. Furthermore, it is well known that very different physical processes in a volcano may produce quite similar results (Schick, 1992). This has been confirmed also by theoretical modelling in the frequency domain of observed spectra of tremor and low-frequency events where it was found that many physical mechanisms could explain them equally well (Nishimura et al., 1995).

In this article we present a review of the methods and source modelling that have been used to study and explain characteristics of volcanic tremor recorded at a number of volcanoes worldwide (Fig. 1). In the first part we describe the general features of tremor signals derived from observations and then we embark on an analysis of the individual methods applied in order to extract useful information about their origin. In the second part, we discuss the efforts to propose models for the tremor source and we group them according to the physical mechanism they employ to explain source characteristics. In order to make the referencing of volcanoes and that of the corresponding articles easier, we have followed the scheme (volcano-author (et al.), year) throughout this paper. Our aim is to give a comprehensive account of the trends and developments in the research about volcanic tremor. The reader may further refer to a large database compiled by Steve McNutt and Milton Garcés accessible via the world wide web (http://www.giseis.alaska. edu/Input/steve) containing 700 references of reported tremor occurrences around the world.

\section{The nature of volcanic tremor}

Volcanic tremor can be formally defined as a persistent seismic signal that is observed only near active volcanoes, lasting from several minutes to several days, preceding and/or accompanying most volcanic eruptions (Fehler, 1983; Julian, 1994; Ripepe, 1996; Métaxian et al., 1997). In most classification schemes (Minakami, 1960; Latter, 1979; Power et al., 1994) the term 'volcanic tremor' is being used in order to describe tremor signals of varying amplitude and duration. Other terms and modifiers have also been used, that characterise the appearance of the signal in the time or frequency domain (Table 1). In order 


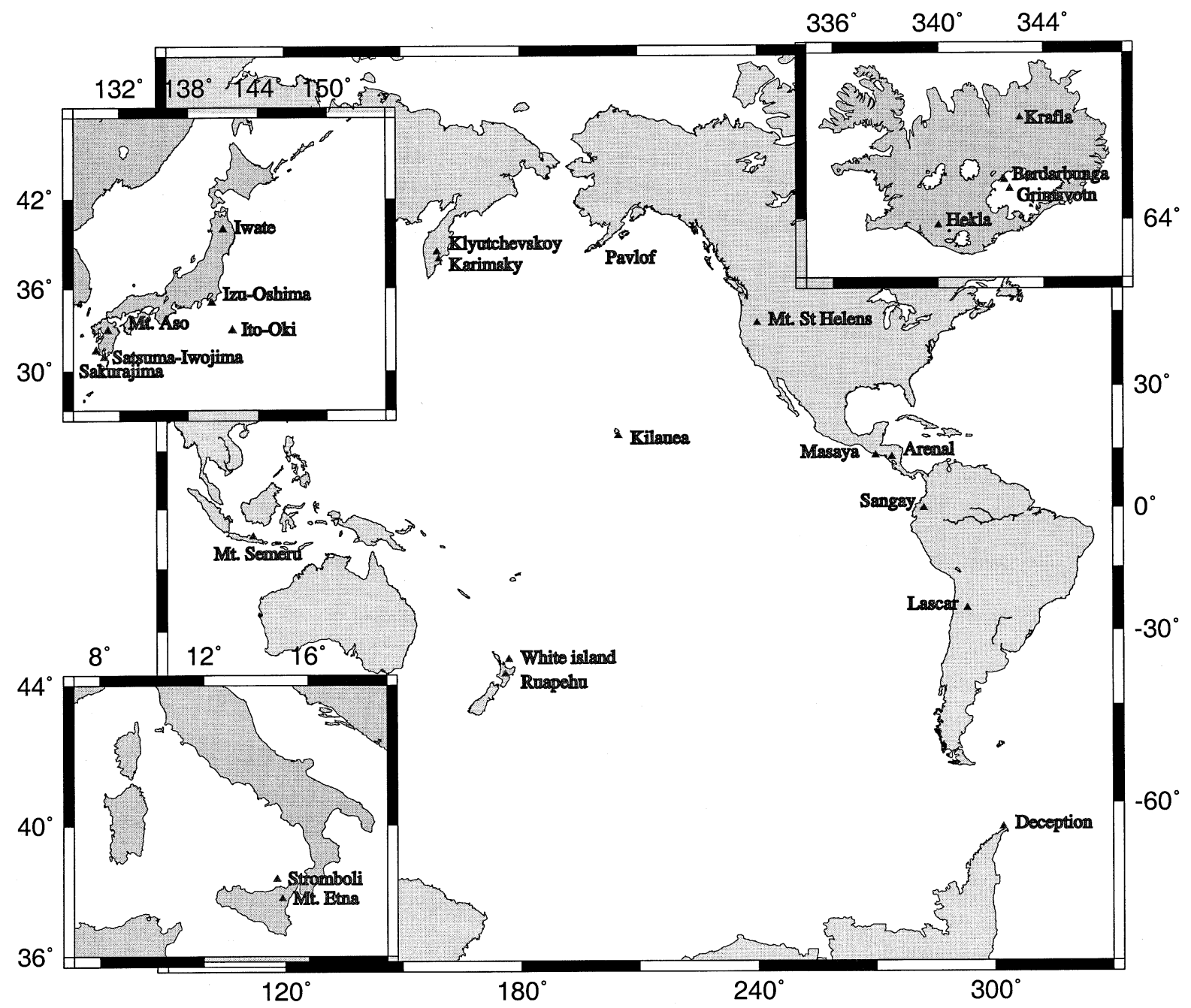

Fig. 1. Location of volcanoes where the tremor occurrences discussed throughout this paper were recorded. The white areas shown in the map of Iceland indicate permanent glaciers of which Vatnajökull is the largest.

to avoid confusion throughout this paper we will make use only of the general term 'volcanic tremor' to describe all such signals.

The majority of volcanic tremor waveforms have an emergent onset (Fig. 2) to the extent that the picking of the first arrival is almost impossible and travel-time location methods used for earthquakes cannot be applied (Hofstetter and Malone, 1986). However, there are notable exceptions with clear impulsive onsets (KilaueaAki and Koyanagi, 1981; Mt. St. Helens-Fehler, 1983) (Fig. 3) that made it possible to locate the source of tremor, e.g. at Kilauea to a depth of about $40 \mathrm{~km}$. Observations regarding the relation of the tremor amplitude with the intensity of the eruptive activity are mixed. In many cases an increase in tremor amplitude coincided with visual observations of strong lava fountaining or dome building (Pavlof-McNutt, 1986; Kilauea-Dvorak and Okamura, 1985; Hekla-Brandsdóttir and Einarsson, 1992). However, in other cases no relationship between superficial activity and amplitude could be identified, suggesting that the temporal variations of the amplitude are a func- 


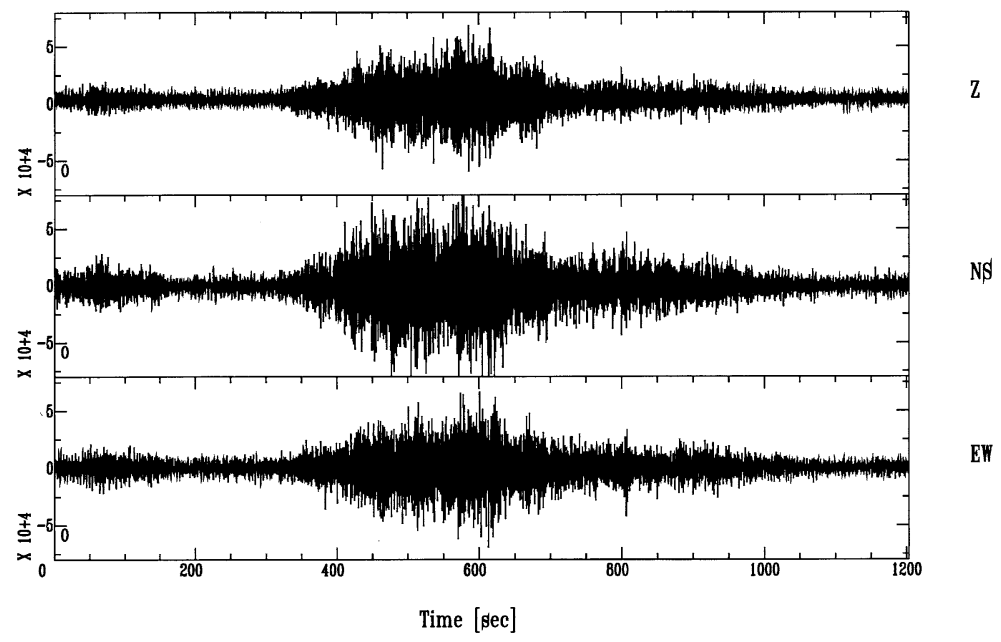

Fig. 2. Velocity waveforms of high-amplitude and background tremor recorded by a three-component seismometer during the onset of the 1996 Vatnajökull subglacial eruption, central Iceland (from Konstantinou et al., 2000).

tion of the flow rate of magma at large depths inside the crust (Kilauea-Ferrazzini and Aki, 1992).

In the frequency domain the tremor signals show a great variation in their spectral content and appearence. As it will be discussed in detail later, this variation may be attributed either to source or path/attenuation effects due to the propagation of the waves through strongly heterogeneous volcanic structures. The power in the spectrum is often concentrated in the band between 0.5 and $7 \mathrm{~Hz}$, bearing in mind the influence of different instrument responses on the calculated spectrum. The shape of the spectrum is usually dominated by one or more sharp peaks that represent either a fundamental frequency and its harmonics (Fig. 4) or a random distribution of peaks (Fig. 5). Temporal variations in the frequency content of tremor have also been observed and it is believed that they reflect source effects (Klyutchevskoy-Gordeev et al., 1990; Sakurajima-Tsuruga et al., 1997).

Unlike the study of the frequency domain, the study of the properties of the wavefield (wave types, polarisation, phase velocities) has not been so thorough, mostly because of the lack of digital three-component data or poor station coverage/ network geometry at the studied areas. In most

Table 1

Terms/modifiers that characterise volcanic tremor in the time or frequency domain

\begin{tabular}{|c|c|c|c|}
\hline Term & Domain & Description & Example \\
\hline Harmonic & Frequency/Time & $\begin{array}{l}\text { Multiple peaks in the spectrum with a fundamental } \\
\text { frequency and its harmonics }\end{array}$ & $\begin{array}{l}\text { Mt. Semeru, Schlindwein } \\
\text { et al., } 1995\end{array}$ \\
\hline Monochromatic & Frequency/Time & $\begin{array}{l}\text { Spectrum consisting of only one sharp peak extending } \\
\text { over a narrow frequency band }\end{array}$ & Ruapehu, Hurst, 1992 \\
\hline Banded & Time & $\begin{array}{l}\text { Tremor bursts separated by periods of quiescence, that } \\
\text { resemble stripes or bands on a seismogram }\end{array}$ & McNutt, 1996 \\
\hline Spasmodic & Time & $\begin{array}{l}\text { Continuous tremor with large amplitude variations, that } \\
\text { probably depend on magma flow or lava fountaining }\end{array}$ & $\begin{array}{l}\text { Krafla, Brandsdóttir and } \\
\text { Einarsson, } 1992\end{array}$ \\
\hline Tremor storm & Time & $\begin{array}{l}\text { Small duration tremor bursts superposed on the } \\
\text { background earthquake activity }\end{array}$ & Etna, Seidl et al., 1990 \\
\hline
\end{tabular}


cases the wavefield consists of Rayleigh and Love waves (Kilauea-Ferrazzini et al., 1991; Mt. EtnaEreditato and Luongo, 1994; Wegler and Seidl, 1997) and is strongly influenced by path effects. There are also a few studies that indicate a mixed composition of the wavefield with the presence of both body and surface waves (Deception Island, Almendros et al., 1997). Other studies utilised data from local arrays, by using the polarisation properties of the wavefield in order to calculate the backazimuth of the propagating waves and estimate the location of the source (Kilauea-Ferrazzini et al., 1991; Masaya-Métaxian et al., 1997).

\section{Methods of analysis applied to volcanic tremor}

\subsection{Spectral analysis}

\subsubsection{Methods of spectral estimation}

In most studies of volcanic tremor the estimation of the frequency content has been one of the primary tools for investigating the nature of the signal. However, any method used for the calculation of the spectrum should be able to cope successfully with a number of characteristics not present in other seismic signals. First, tremor can persist for long periods of time resulting in

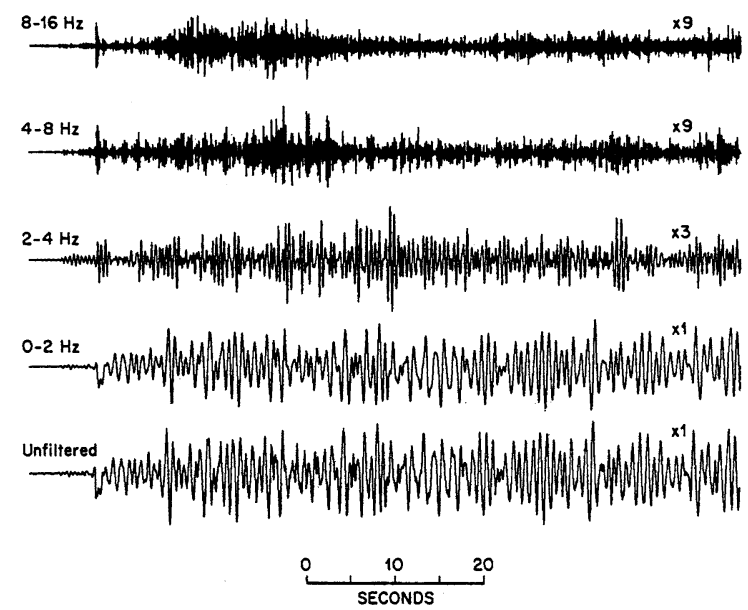

Fig. 3. Velocity waveform of a tremor episode with impulsive onset, recorded during the 1980 eruption of Mt. St. Helens and filtered traces (from Fehler, 1983; ${ }^{\circ} \mathrm{AGU}$, reproduced with permission of American Geophysical Union).
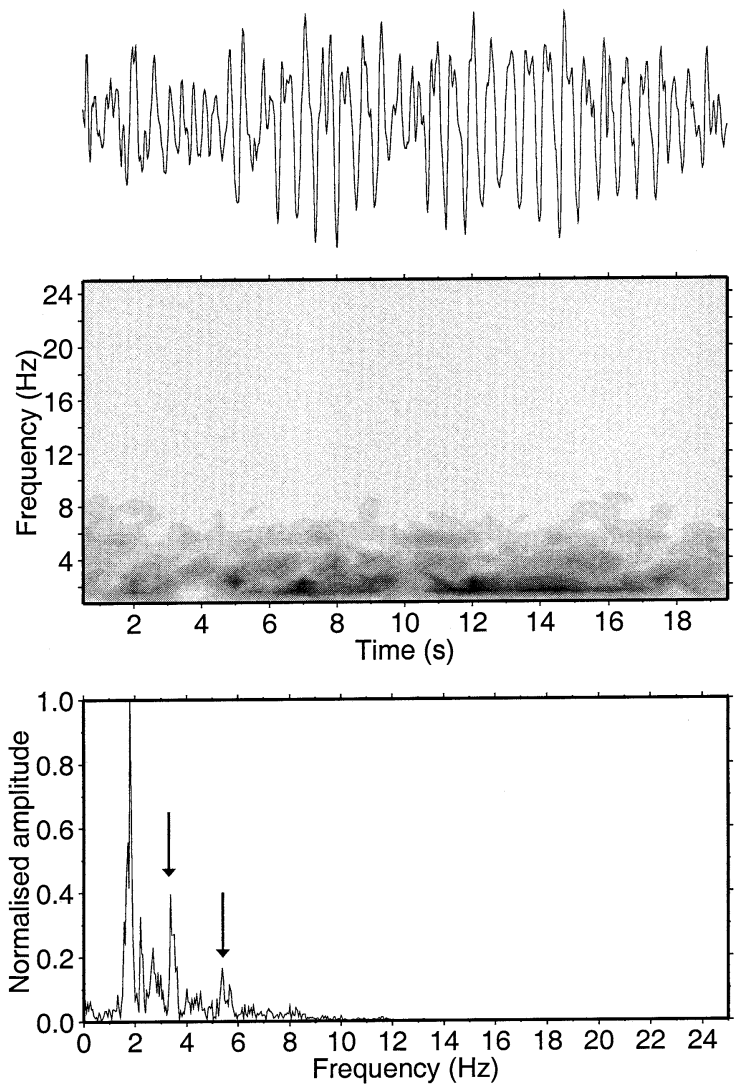

Fig. 4. Velocity waveform, spectrogram and amplitude spectrum of $20 \mathrm{~s}$ of harmonic tremor recorded at White Island. The dark shades in the spectrogram indicate high energy and light shades low energy. The harmonics are marked with arrows. This kind of tremor occurs rarely at White Island during periods when there is no eruptive activity (from Sherburn et al., 1998).

the accumulation of large amounts of data that have to be analysed. Second, they may exhibit strong temporal variations in amplitude and/or frequency content that should be monitored, because of their importance for source modelling and eruption forecasting. Third, the calculated spectrum may have multiple sharp peaks around narrow frequency bands, in which case a high degree of resolution is required in order to resolve the individual frequencies. One of the first spectral methods to be applied to digital tremor data was the direct segment method (Båth, 1974). The long tremor time series is divided into smaller nonoverlapping segments and the spectrum is calcu- 

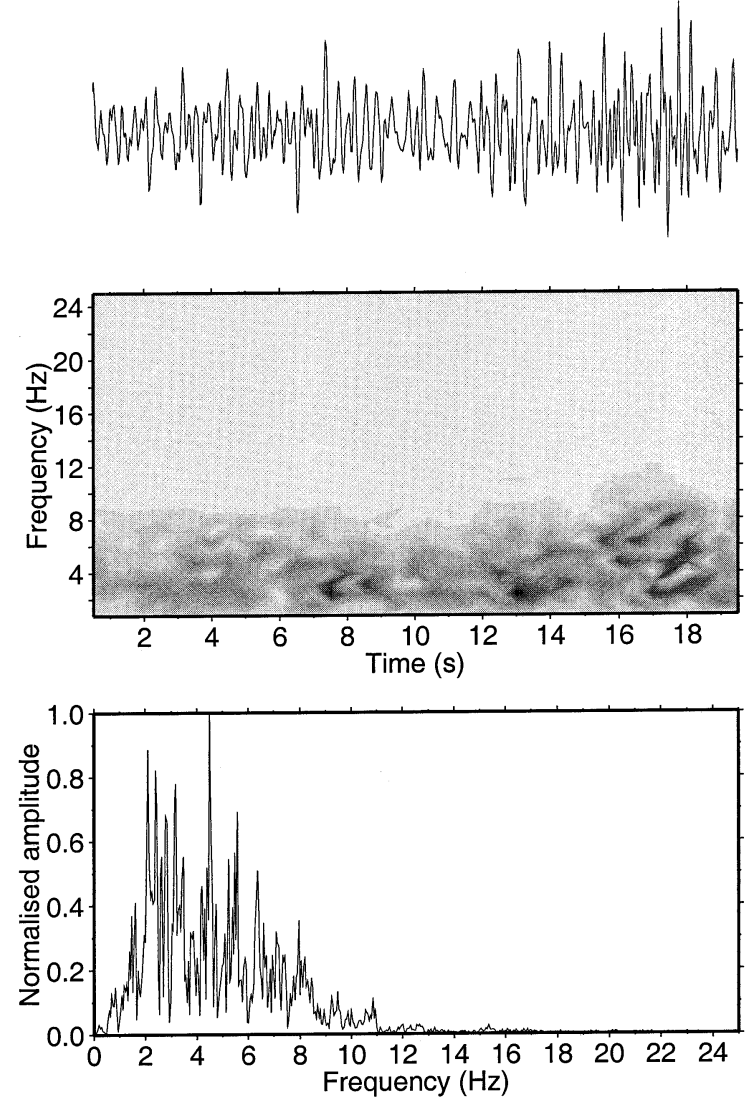

Fig. 5. Velocity waveform, spectrogram and amplitude spectrum of $20 \mathrm{~s}$ of inharmonic tremor recorded at White Island. The shades in the spectrogram are as in Fig. 5. In contrast to the harmonic tremor of Fig. 4, inharmonic tremor is very common at White Island and usually accompanies volcanic activity (from Sherburn et al., 1998).

lated for each segment by means of a Fast Fourier Transform (FFT). The final spectral estimate is then the average of all the individual spectra. This method has been used in volcanic tremor recordings from Mt. St. Helens (Fehler, 1983; Hofstetter and Malone, 1986). It enhances the spectral peaks that are common to every time seg-

Fig. 6. (A) Amplitude spectra of tremor from Ruapehu showing a peak at $0.8 \mathrm{~Hz}$ (marked with arrow) and peaks at 2 and $7 \mathrm{~Hz}$. The spectra are an average of 129 3-min readings over a period of $6.5 \mathrm{~h}$ from three different stations (after Sherburn et al., 1999). (B) Same as in (A) for tremor with peaks at 2 and $3 \mathrm{~Hz}$ and wideband tremor (after Sherburn et al., 1999). ment and suppresses those generated by random noise. A similar method for real-time spectral estimation of tremor data has been implemented at the Ruapehu volcano observatory (Hurst, 1985),

A
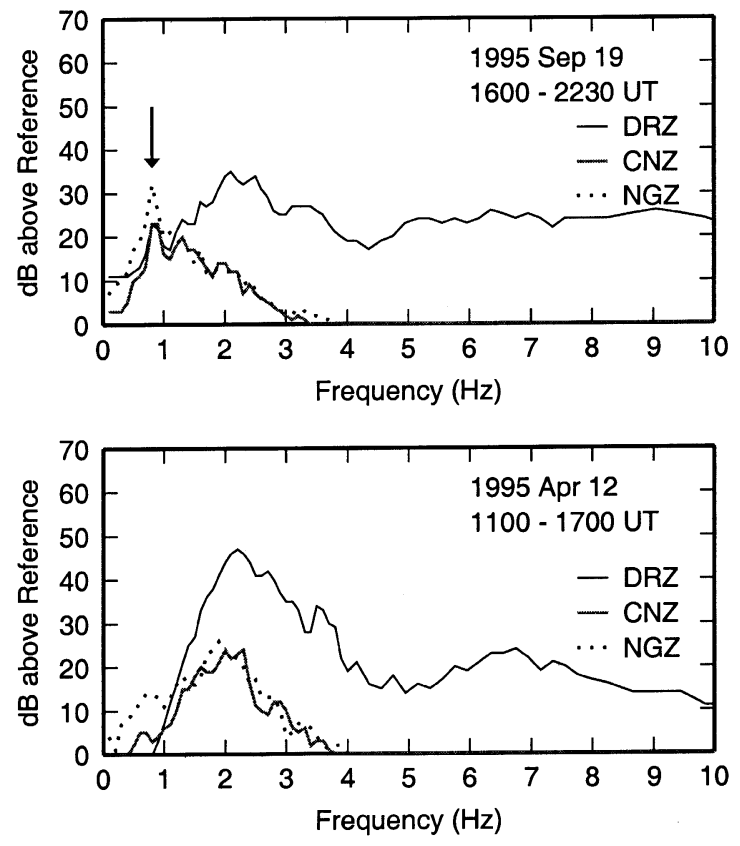

B
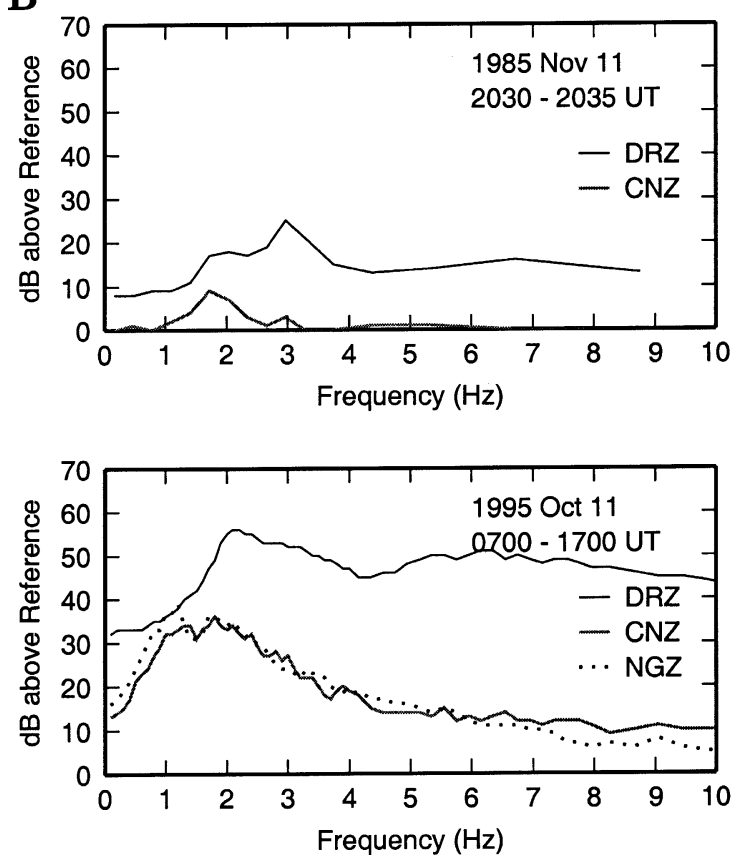


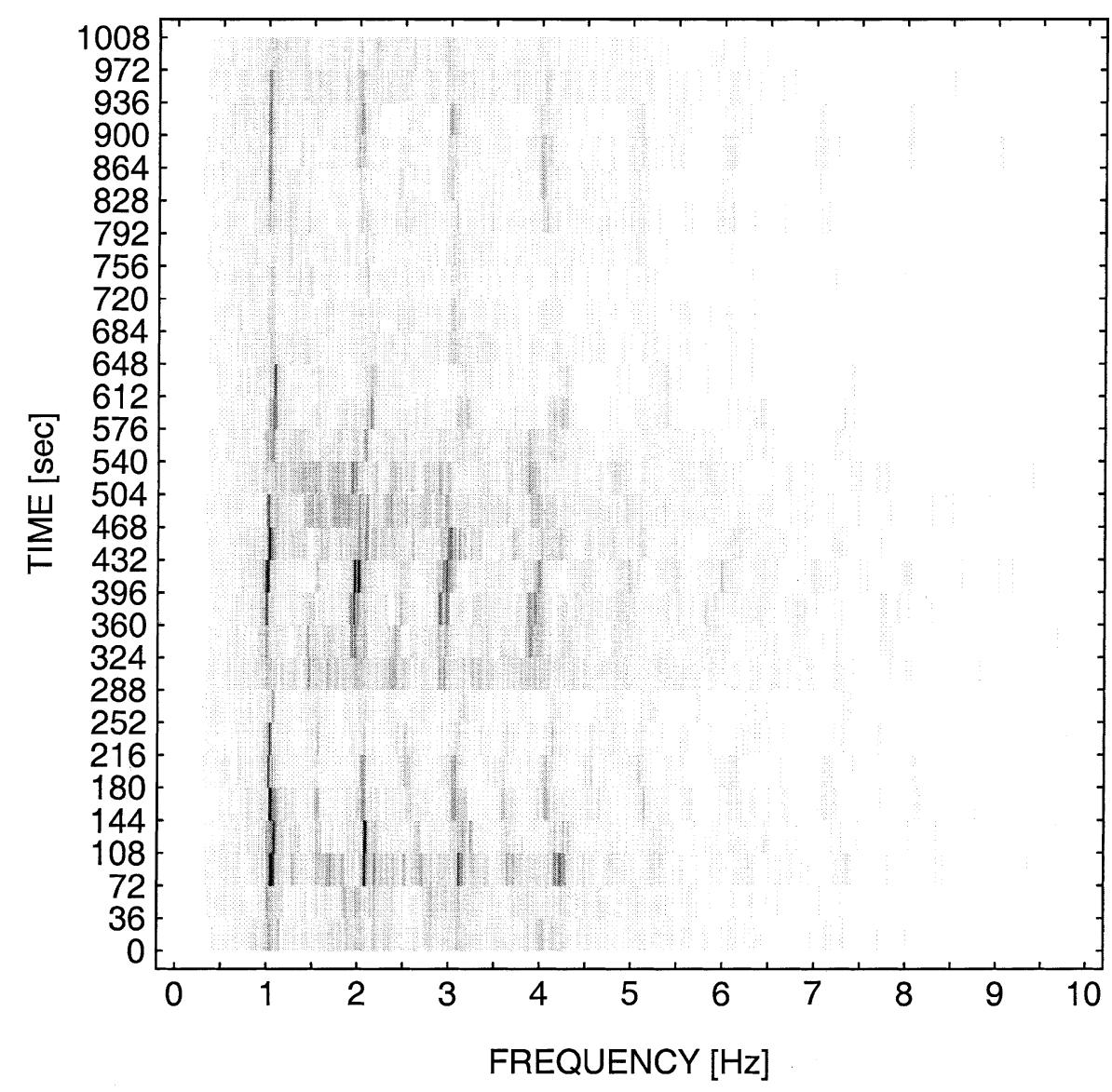

Fig. 7. Spectrogram of tremor recorded at Mt. Semeru with 10 harmonics clearly visible. The vertical axis marks the beginning of every calculation window and dark shades indicate high energy, light shades low energy. Note how the spectral lines representing each harmonic shift as time elapses, keeping the same horizontal distance from each other; this phenomenon, which has been termed 'gliding', was also observed at Arenal volcano by Hagerty et al. (2000) (from Schlindwein et al., 1995; ${ }^{\circ}$ AGU, reproduced with permission of American Geophysical Union).

where average spectra are calculated over successive 3-min intervals with a frequency resolution of $0.1 \mathrm{~Hz}$ in the band between 0.05 and $4.04 \mathrm{~Hz}$ (Sherburn et al., 1999) (Fig. 6A,B).

In order to detect temporal changes in the frequency content of the signal a direct comparison of the averaged spectra should be performed. Such a comparison of spectra from different time periods is feasible only when the amount of data is relatively small and the observed variations are larger than the ambient noise levels. A better way of detecting temporal variations is by incorporating in the display all the variables that are likely to change (time, frequency, amplitude).
This is accomplished by creating a spectrogram (Fig. 7), which is a 2D representation of the variations of spectral amplitude and frequency of the observed signal as time elapses. The calculation of the spectrogram can be achieved by moving a sliding window over the whole length of the time series and estimating the amplitude spectrum by performing an FFT for overlapping positions of the window (e.g. Mt. Semeru-Schlindwein et al., 1995; Ruapehu-Sherburn et al., 1999).

The resolution of the spectrum obtained by using an FFT algorithm is proportional to the reciprocal of the window length chosen for the analysis. In order to increase the spectral resolution 
more than it is possible with the FFT, the Maximum Entropy Method (MEM) (Burg, 1967) has been applied in a number of cases (PavlofMcNutt, 1986; Izu-Oshima-Yamaoka et al., 1991; Mt. Etna-Seidl et al., 1990). Assuming that the time series is generated by a linear random mechanism MEM fits to the data, in a least squares sense, an autoregressive process of order $p$ of the form (detailed derivations of these equations can be found in Ulrych and Bishop (1975)):

$y_{t}=\alpha_{1} x_{t-1}+\alpha_{2} x_{t-2}+\ldots+\alpha_{p} x_{t-p}+r_{t}$

by applying a prediction filter of length $p$, where $\alpha$ are the filter coefficients calculated by solving the normal equations posed by the least squares problem, $r_{t}$ is a white noise series with zero mean and $\sigma_{a}^{2}$ variance. Then the spectrum of $y_{t}$ will be estimated by the equation:

$$
Y(\omega)=\frac{2 \sigma_{a}^{2}}{\left|1-\sum_{i=1}^{M} \alpha_{i} \exp (-i 2 \pi \omega j)\right|^{2}}
$$

where $\omega$ is frequency and $M$ represents the total number of samples in the time series considered for the analysis. If the selected time window of the data is small enough MEM will produce a much higher resolution spectrum than the usual FFT methods, otherwise the result will be essentially the same. Table 2 gives an account of the different volcanoes where the methods discussed in this section were used, along with some spectral characteristics in each case.

\subsubsection{Identification of source effects from observed spectra}

Any recorded seismic signal can be considered as the result of the consecutive application of a series of linear filters to the original wavelet generated by a source (Lay and Wallace, 1995). This can be represented mathematically by the convolution of one filter with the other in the time domain:

$W(\mathrm{t})=S(\mathrm{t}) * P(\mathrm{t}) * R(\mathrm{t}) * I(\mathrm{t})$

or the equivalent equation in the frequency domain:

$W(\omega)=S(\omega) P(\omega) R(\omega) I(\omega)$

where $W(\mathrm{t})$ is the recorded waveform, $S(\mathrm{t})$ is the original source wavelet, $P(\mathrm{t})$ represents the filter

Table 2

Spectral characteristics and methods of spectral analysis applied to volcanic tremor

\begin{tabular}{llll}
\hline Region & $\begin{array}{l}\text { Frequency content } \\
(\mathrm{Hz})\end{array}$ & Method applied & Reference \\
\hline Mt. St. Helens & $1-2.1^{\mathrm{a}, \mathrm{b}}$ & Direct segment & Fehler, 1983; Hofstetter and Malone, 1986 \\
Pavlof & $0.7-3^{\mathrm{a}}$ & FFT, MEM & McNutt, 1986; Garcés and Hansen, 1998 \\
Kilauea & $1-8^{\mathrm{b}}$ & FFT overlapping windows & Aki and Koyanagi, 1981; Ferrazzini and Aki, 1992 \\
Klyutchevskoy & $0.5-5^{\mathrm{b}}$ & Direct segment & Gordeev et al., 1990 \\
Ruapehu & $2,3,7^{\mathrm{a}, \mathrm{b}}$ & FFT overlapping windows & Hurst, 1992; Sherburn et al., 1999 \\
Mt. Aso & 0.1 & FFT & Sassa, 1936; Kawakatsu et al., 1994 \\
Deception Island & $1-8$ & FFT overlapping windows & Almendros et al., 1997; Vila et al., 1992 \\
Mt. Semeru & $1-5^{\mathrm{a}, \mathrm{b}}$ & FFT overlapping windows & Schlindwein et al., 1995 \\
Arenal & $0.9-7.2^{\mathrm{b}}$ & FFT/periodogram & Benoit and McNutt, 1997; Hagerty et al., 2000 \\
White Island & $1-8^{\mathrm{a}, \mathrm{b}}$ & FFT overlapping windows & Sherburn et al., 1998 \\
Stromboli & $0.1-8$ & FFT & Ripepe et al., 1996; Chouet et al., 1999 \\
Mt. Etna & $0.25-5$ & FFT, MEM & Seidl et al., 1980; Schick et al., 1982; Seidl et al., 1990 \\
Ito-Oki & $1-7^{\mathrm{a}}$ & FFT overlapping windows & Ukawa, 1993 \\
Izu-Oshima & $0.7-8$ & MEM & Yamaoka et al., 1991 \\
Lascar & $0.63,30$ integer & FFT & Hellweg, 1999, 2000 \\
& overtones & & \\
\hline
\end{tabular}

\footnotetext{
a Data from short-period sensors were used for the spectral calculations.
}

b Temporal variations of the frequency content observed. 
characteristics due to the propagation of the signal through the Earth, $R(\mathrm{t})$ represents filtering effects due to the structure beneath the recording station and $I(\mathrm{t})$ accounts for the filtering due to limited frequency bandwidth of the recording instrument. Hereafter we will refer to $S(\mathrm{t}), P(\mathrm{t})$ and $R(\mathrm{t})$ filters as 'source', 'path' and 'site effects' respectively.

Since in most cases the resulting spectrum consists of a series of sharp peaks, a major difficulty is to successfully determine which factors have shaped it. A comparison between tremor and earthquake spectra recorded at the same station is a common method of checking for possible site effects, since they should influence both signals (Mt. St. Helens-Fehler, 1983; Kilauea-Goldstein and Chouet, 1994; Deception Island-Almendros et al., 1997). Unfortunately it is far more difficult to find and isolate path effects, mainly because of the limited knowledge of the structure between the source and the receivers in most volcanic areas. If the recording stations are close enough and azimuthally distributed around the source, similarities in spectra of different stations may be attributed to source effects (e.g. PavlofMcNutt, 1986).

A less empirical approach to the source-path effect separation problem involves the use of spectral ratios for pairs of events recorded at a number of stations (Sakurajima-Tsuruga et al., 1997). The method uses two time windows A and B from a tremor time series that were recorded at several different stations. Based on the assumption that these two events are generated by the same source and at the same hypocentral area, the path and site effects will be the same, thus Eq. 4 will be yielding spectral ratios of the form $S^{\mathrm{A}}(\omega)_{i} / S^{\mathrm{B}}(\omega)_{i}$ for the $i$ th station. The correlation of the estimated ratios for all the stations and for different frequency bands can be checked by performing a statistical covariance analysis, where high correlation coefficients should indicate a common source effect for the two events. This method may not be always applicable, since the assumptions for events generated by the same source and at the same depth are not generally valid in every volcanic environment.

The problem of the correct identification of spe- cific frequencies as source effects and not as propagational artefacts has been made easier with the widespread use of spectrograms that display any new frequency as it appears. Since the path and site effect factors listed in Eq. 3 behave as linear filters and cannot generate new frequencies to their input signal (Anstey, 1981), these frequencies can only be attributed to a source effect.

\subsection{Study of the wavefield properties}

\subsubsection{Polarisation analysis}

A further step in the analysis of volcanic tremor is the study of its wavefield and the identification of the types of waves that compose it. The standard method that has been used for such an analysis is that of the covariance matrix (Montalbetti and Kanasewich, 1970; Jurkevics, 1988) which utilises data recorded by one or more three-component seismometers. The method works in the time domain by bandpass filtering the signal around the frequency band of interest and then calculating the covariance matrix for a short, sliding time window along the time series by using the following equation:

$S_{i j}=\frac{\boldsymbol{X} \boldsymbol{X}^{T}}{N}=\frac{1}{N} \sum_{i=1}^{N} x_{i j} x_{i k}$

where $\mathbf{X}=\left[x_{i j}\right] ; i=1,2, \ldots, N ; j=1,2,3$; is the data matrix in one window and $x_{i j}$ is the $i$ th sample of component $j, N$ is the number of samples and $T$ denotes the transpose of $\mathbf{X}$. The estimated covariance matrix $S$ will be of the form:

$\boldsymbol{S}=\left(\begin{array}{ccc}S_{\mathrm{zz}} & S_{\mathrm{zn}} & S_{\mathrm{ze}} \\ S_{\mathrm{zn}} & S_{\mathrm{nn}} & S_{\mathrm{ne}} \\ S_{\mathrm{ze}} & S_{\mathrm{ne}} & S_{\mathrm{ee}}\end{array}\right)$

where $\mathrm{z}, \mathrm{n}$, e denote the vertical, north-south and east-west components respectively and $S_{\mathrm{ze}}$ is the cross-variance of the vertical and east-west components, while $S_{\mathrm{zz}}$ is the auto-variance of the vertical component. Solving the eigenvalue problem $\left(\mathbf{S}-\lambda^{2} \mathbf{I}\right) \mathbf{u}=\mathbf{0}$ will give the three eigenvalues $\left(\lambda_{1}, \lambda_{2}\right.$, $\left.\lambda_{3}\right)$ and their corresponding eigenvectors $\left(\mathbf{u}_{1}, \mathbf{u}_{2}\right.$, $\mathbf{u}_{3}$ ). The three principal axes of the polarisation 
ellipsoid will be given by $\lambda_{j} \mathbf{u}_{j}$, with $j=1,2,3$; the eigenvectors are the axis orientations and their lengths are equal to $\lambda_{j}$ in amplitude units. One non-zero eigenvalue implies a purely rectilinear ground motion, while two non-zero eigenvalues characterise a purely elliptical polarisation. In order to obtain a measure of what kind of motion prevails in the time window the rectilinearity and planarity coefficients are used, that are given by $1-\left(\lambda_{2}+\lambda_{3}\right) / 2 \lambda_{1}$ and $1-2 \lambda_{3} /\left(\lambda_{1}+\lambda_{2}\right)$ respectively.

The method described above has been used to study the wavefield properties of volcanic tremor from Mt. Etna for a time period spanning 6 years (1987-1993) during which different kinds of volcanic activity were at work, including periods of quiescence, Strombolian activity or lava fountaining (Ferrucci et al., 1990; Ereditato and Luongo, 1994; Wegler and Seidl, 1997). The polarisation analysis for the whole of this period revealed a persistent pattern of high values for the rectilinearity coefficient with an east-west polarisation, suggesting that the wavefield consists of waves radiated by a vertical extended source aligned along the north-south direction. The dominant wave types have been identified either as $P$ waves (Ferrucci et al., 1990) or as Love/SH waves (Ereditato and Luongo, 1994; Wegler and Seidl, 1997) showing a complicated overlapping pattern. Similar observations have been reported for the tremor wavefield in other volcanoes, such as Arenal where the dominant wave type was identified as S waves by Benoit and McNutt (1997), whereas Hagerty et al. (2000) reported a very complicated composition of the wavefield and were unable to identify any particular wave type.

\subsubsection{Study of the wavefield and source location using array methods}

\subsubsection{Method of correlation coefficients}

While polarisation analysis can give a qualitative picture of the composition of the tremor wavefield (even using data from only one seismometer), array methods can provide a much more detailed knowledge of it, at the expense of having to use more instruments and a specific receiver geometry. Aki (1957) designed and used the method of correlation coefficients in order to identify the predominant wave type of the background seismic noise generated by traffic in Tokyo. The method assumes that the recorded seismic signal is stationary and stochastic in time and space and that it consists mostly of surface waves, implying that the method can resolve wavefield properties generated by shallow sources.

The spatial correlation function is calculated for pairs of receivers, one being at the centre of a semicircular array (reference receiver) and the others at its circumference, covering an azimuth of 0 to $\pi$ degrees. This function is defined as:

$\phi(r, \varphi)=\langle u(x, y, t) \cdot u(x+r \cos \varphi, y+r \sin \varphi, t)\rangle$

where the angle brackets denote averaging over time, $(x, y)$ and $(x+r \cos \varphi, y+r \sin \varphi)$ are the Cartesian coordinates of the two receivers, $r$ is the distance between them and $\varphi$ is the azimuth of the two receivers measured from the direction of the $x$ axis. Integrating this function for the azimuth range covered by the array will give:

$\phi(\bar{r})=\frac{1}{\pi} \int_{0}^{\pi} \phi(r, \varphi) \mathrm{d} \varphi$

For a wave with a phase velocity $c(\omega)$ the azimuthally averaged correlation function is related to the power spectrum $\Phi(\omega)$ by the equation:

$\phi(\bar{r})=\frac{1}{\pi} \int_{0}^{\infty} \Phi(\omega) J_{0}\left[\frac{\omega}{c(\omega)} r\right] \mathrm{d} \omega$

where $J_{0}$ is the Bessel function of zero order. In almost all the cases one or more specific frequency bands are of interest: filtering the signal through a narrow bandpass filter centred at $\omega_{0}$, the power spectrum will be $\Phi(\omega)=P\left(\omega_{0}\right) \delta\left(\omega-\omega_{0}\right)$, where $P\left(\omega_{0}\right)$ is the spectral power density of the signal at frequency $\omega_{0}$ and $\delta$ is the Dirac function. The correlation function will become:

$\phi\left(\bar{r}, \omega_{0}\right)=\frac{1}{\pi} P\left(\omega_{0}\right) J_{0}\left[\frac{\omega_{0}}{c\left(\omega_{0}\right)} r\right]$

The correlation coefficient $\rho\left(r, \varphi, \omega_{0}\right)$ can then be defined as: 

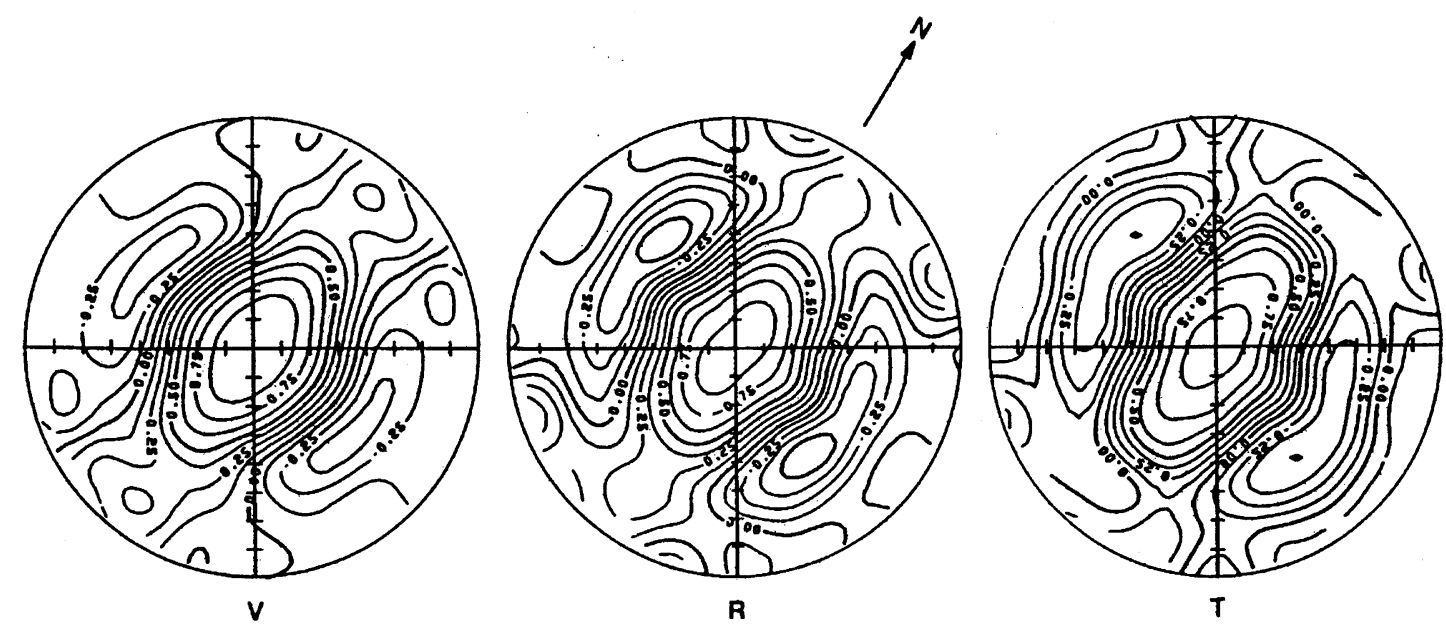

Fig. 8. Contour maps of the correlation coefficients $\rho\left(r, \varphi, \omega_{0}\right)$ calculated from tremor data recorded at Kilauea (Pu'u O'o crater) over a window of $180 \mathrm{~s}$. The three plots correspond from left to right to the vertical, radial and transverse component. The frequency axis is taken along the radius of the circle with the origin at the centre. Note the rapid decrease of values along the EW direction, while they remain almost constant along the NS which is the direction that the wavefront is oriented (from Ferrazzini et al., 1991; ${ }^{\odot} \mathrm{AGU}$, reproduced with permission of American Geophysical Union).

$\rho\left(r, \varphi, \omega_{0}\right)=\frac{\phi\left(r, \varphi, \omega_{0}\right)}{\phi\left(0, \varphi \omega_{0}\right)}$

and the azimuthal average of the correlation coefficients will be equal to:

$\bar{\rho}\left(r, \omega_{0}\right)=J_{0}\left[\frac{\omega_{0}}{c\left(\omega_{0}\right)} r\right]$

It is possible therefore to calculate the correlation coefficients for different values of $\omega$ and azimuth $\varphi$, then fit a Bessel function to the coefficients and recover the phase velocity $c\left(\omega_{0}\right)$ of the recorded waves. By further analysis of the dispersion curves one may obtain the $2 \mathrm{D}$ velocity structure beneath the array for depths ranging $100 \mathrm{~m}$ to $1 \mathrm{~km}$. The equations that relate the correlation coefficients with the phase velocities of different wave types (Rayleigh, Love) can be found in Aki (1957, 1959). A contour map of the coefficients versus azimuth and frequency (Fig. 8) is used in order to determine the backazimuth of the incoming waves. Assuming that a plane wave is propagating at a fixed azimuth $\theta$, the correlation coefficient will be:

$$
\begin{aligned}
& \rho\left(r, \varphi, \omega_{0}\right)=\cos \left[\frac{\omega_{0} r}{c\left(\omega_{0}\right)} \cos (\theta-\varphi)\right]= \\
& \quad \cos \left[\omega_{0} \tau\left(r, \varphi, \omega_{0}\right)\right]
\end{aligned}
$$

where $\tau$ is the time delay between two receivers separated by distance $r$ at an azimuth $\varphi$. In this sense $\rho$ is constant along the wavefront $(\varphi=\theta \pm \pi)$ 2 ) and decays in a direction perpendicular to it $(\varphi=\theta)$.

Open conduit volcanoes that exhibit either permanent degassing or regular lava fountaining activity are good candidates for applying the correlation method, since the tremor source can be considered to a good approximation stationary and it is shallow enough to excite sufficient surface waves. The application of the method in three different volcanic systems (Kilauea-Ferrazzini et al., 1991; Masaya-Métaxian et al., 1997; Stromboli-Chouet et al., 1998) showed that the recorded waves were coming from the summit crater of each volcano, where most of the activity was visually observed. In the case of Masaya volcano, two arrays were available for the application of the method and the intersection of their backazimuth directions was used to locate the tremor source. Although at Masaya and Strom- 
boli the tremor wavefield was found to consist of both Rayleigh and Love waves, at Kilauea only Rayleigh waves could be identified after the study of their dispersion curves.

\subsubsection{Semblance methods for source location}

A realistic visualisation of the tremor source should not only account for the temporal evolution of its properties, but should also extend spatially over some volume underneath a volcano, representing possibly a channel geometry over a magma reservoir or hydrothermal fluid circulation through a system of cracks. The methods discussed so far can pinpoint the area of origin of tremor, but cannot delineate it in three or even two dimensions. Furumoto et al. $(1990,1992)$ attempted to image the source of tremor at IzuOshima volcano using a portable array of vertical component seismometers. The array was situated near the crater and recorded tremor during a fissure formation episode. Their approach was to take advantage of the available multichannel data by calculating the semblance (Neidel and Tanner, 1971) which is defined as:

$$
S=\frac{\left.\sum_{j=1}^{L}\left(\sum_{i=1}^{N} f_{i, j(i)}\right)\right)^{2}}{N \sum_{j=1}^{L} \sum_{i=1}^{N} f_{i, j(i)}^{2}}
$$

where $N$ is the number of stations, $f_{i, j(i)}$ is a seismogram recorded at the $i$ th station in the $j$ time sample and $L$ is the number of samples that de- fines a time window. Assuming that the coherency of the signal is being maximised in certain time windows because of phases arriving from a source, it is possible to calculate source-receiver travel times by changing the source location on a $2 \mathrm{D}$ or $3 \mathrm{D}$ grid of nodes and evaluating the semblance for each window specified by these travel times (Gottschämmer and Surono (2000) applied a similar grid based method in order to locate the tremor source at Bromo volcano, but used signal power instead of semblance). In this way the spatial distribution of the semblance values can be depicted with the higher values covering the area of the seismic source.

In the case of Izu-Oshima only the high frequency $(5-25 \mathrm{~Hz})$ part of the recorded tremor was analysed using the method outlined above, because Furumoto et al. (1990, 1992) noted that inclusion of larger wavelengths would have resulted in the deterioration of spatial resolution due to the small aperture of the array $(500 \mathrm{~m})$. The semblance distribution showed two separate areas with high values inside the caldera, which also coincided with the tips of the fissure that was formed during the eruption. Furumoto et al. (1992) suggest that these two source regions are the tips of an expanding crack, formed by magma forcing its way up to the surface. The high frequency tremor was then interpreted as the result of the brittle fracture of rock owing to fluid-solid interaction as magma is being injected in the crack.

An expanded definition of semblance has been used in order to locate the source region of vol-

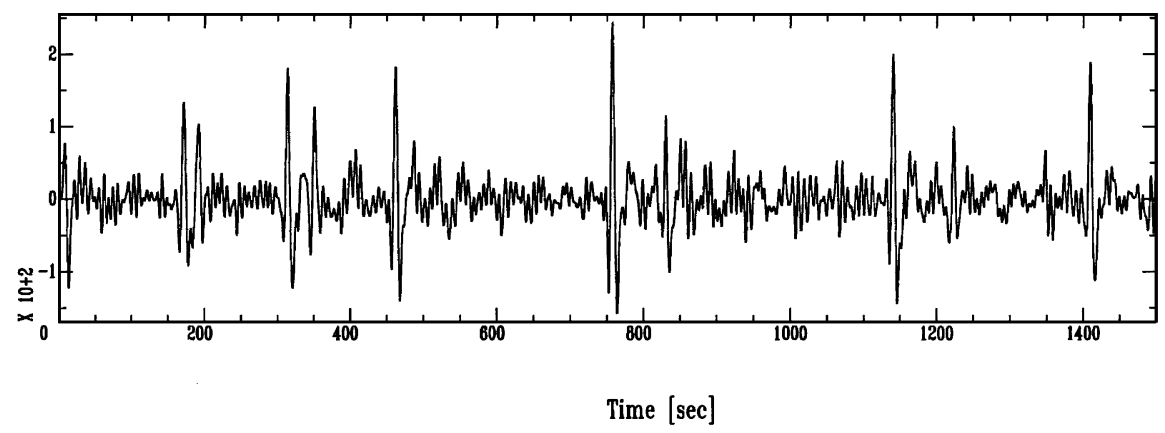

Fig. 9. Vertical velocity waveform of very long period tremor recorded at Pu'u O'o crater, Hawaii. The trace has been bandpass filtered between 0.01 and $0.1 \mathrm{~Hz}$ (from Bond, 2000). 
canic tremor with a dominant period of 7-10 s (Mt. Etna-Seidl et al., 1981; Stromboli-Chouet et al., 1999; Mt. Aso-Kawakatsu et al., 1994, 2000; Mt. Erebus-Rowe et al., 2000; Iwate-Nishimura et al., 2000). This kind of tremor appears in the time domain more as a swarm of discrete pulses rather than continuous episodes (Fig. 9); it occurs even when no signs of volcanic activity are observed and the particle motion indicates a high degree of rectilinearity with a direction pointing from each station to the crater of the volcano. In this case it is reasonable to assume that the source is isotropic and use the radial component $(R)$ from each station in order to calculate the semblance, penalising any departure from a pure rectilinear motion (caused by propagation effects) by subtracting the other components $(V, T)$. The semblance will be:

$$
S=\frac{\sum_{j=1}^{N}\left[\left(\sum_{i=1}^{N} R_{i, j(i)}\right)^{2}-N\left(\sum_{i=1}^{N} V_{i, j(i)}^{2}\right)-N\left(\sum_{i=1}^{N} T_{i, j(i)}^{2}\right)\right]}{N \sum_{j=1}^{L} \sum_{i=1}^{N} R_{i, j(i)}^{2}}
$$

This definition takes advantage not only of a large number of stations that improve the signal to noise ratio, but it also incorporates independent information about the tremor wavefield, such as the rectilinearity. Kawakatsu et al. (2000) call this semblance 'waveform semblance' and use it to locate the source region of the long-period tremor in a similar manner to that of Furumoto et al. $(1990,1992)$ (Fig. $10)$.
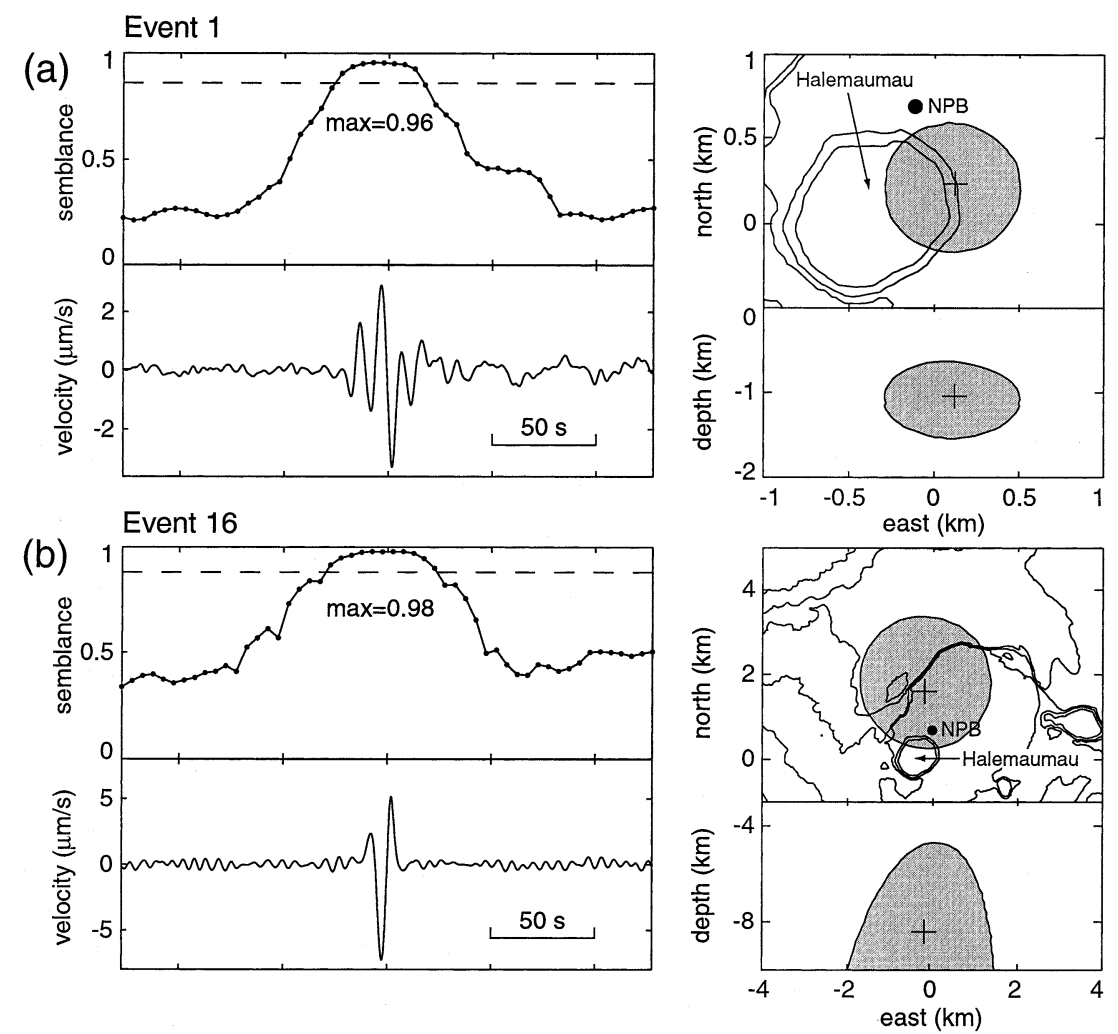

Fig. 10. Example of location of two very long-period tremor events using the waveform semblance method, from Pu'u O'o crater, Hawaii. The source position in the maps and the depth cross-sections on the right is represented by a cross, while the shaded area shows the size of the error region (from Almendros et al., 2002; ${ }^{\circ}$ RAS, reproduced with permission of Blackwell Science). 

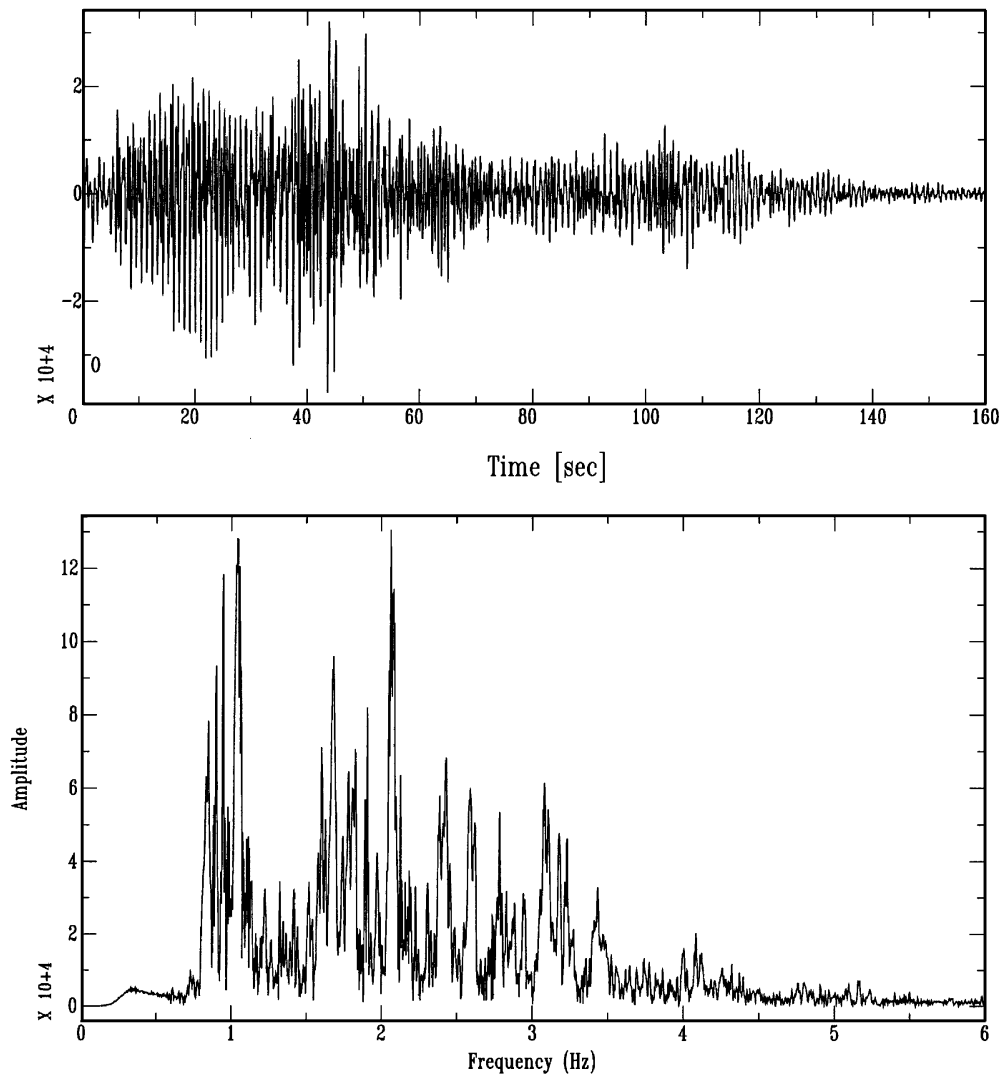

Fig. 11. Vertical component velocity waveform (bandpass filtered $0.3-10 \mathrm{~Hz}$ ) and amplitude spectrum of a tremor episode recorded at Sangay volcano, Ecuador. This kind of quasi-periodic tremor has been termed a 'chugging' event and is commonly accompanied by a sound resembling that of a steam locomotive. Similar events to this have been also observed at Arenal volcano, Costa Rica by Benoit and McNutt (1997) (after Johnson and Lees, 2000).

\subsection{Visual and acoustic observations related to tremor activity}

An important way of gaining insight into the physical processes that generate tremor and other volcanoseismic phenomena is the visual monitoring of the eruptive activity. Even though a range of different factors may be involved when it comes to a decision for conducting such observations (accessibility to the erupting site, possible danger posed to the lives of the scientific crew, use of different type of instruments like video cameras, etc.) the independent information that will be collected may play a significant role for explaining possible physical mechanisms. Detailed visual observations described by Ferrazzini and Aki (1992) during a seismic experiment at Kilauea combined with instrument recordings enabled them to distinguish between the different physical mechanisms that generate tremor and spindle-shaped signals called gas-piston events (Swanson et al., 1979). High-amplitude tremor was being recorded during the first month of the experiment and visual observations around the crater indicated lava fountaining activity while glows could be seen at night. A decrease in the tremor amplitude marked the onset of gas-piston events reflecting a change in the volcanic activity: the level of the lava lake in the crater started rising, with upwelling domes appearing at the surface of the lake and bursting of gas bubbles started occurring. After that the level of the lake fell, but the same kind of ponding and withdrawal of lava continued in episodic cycles. 

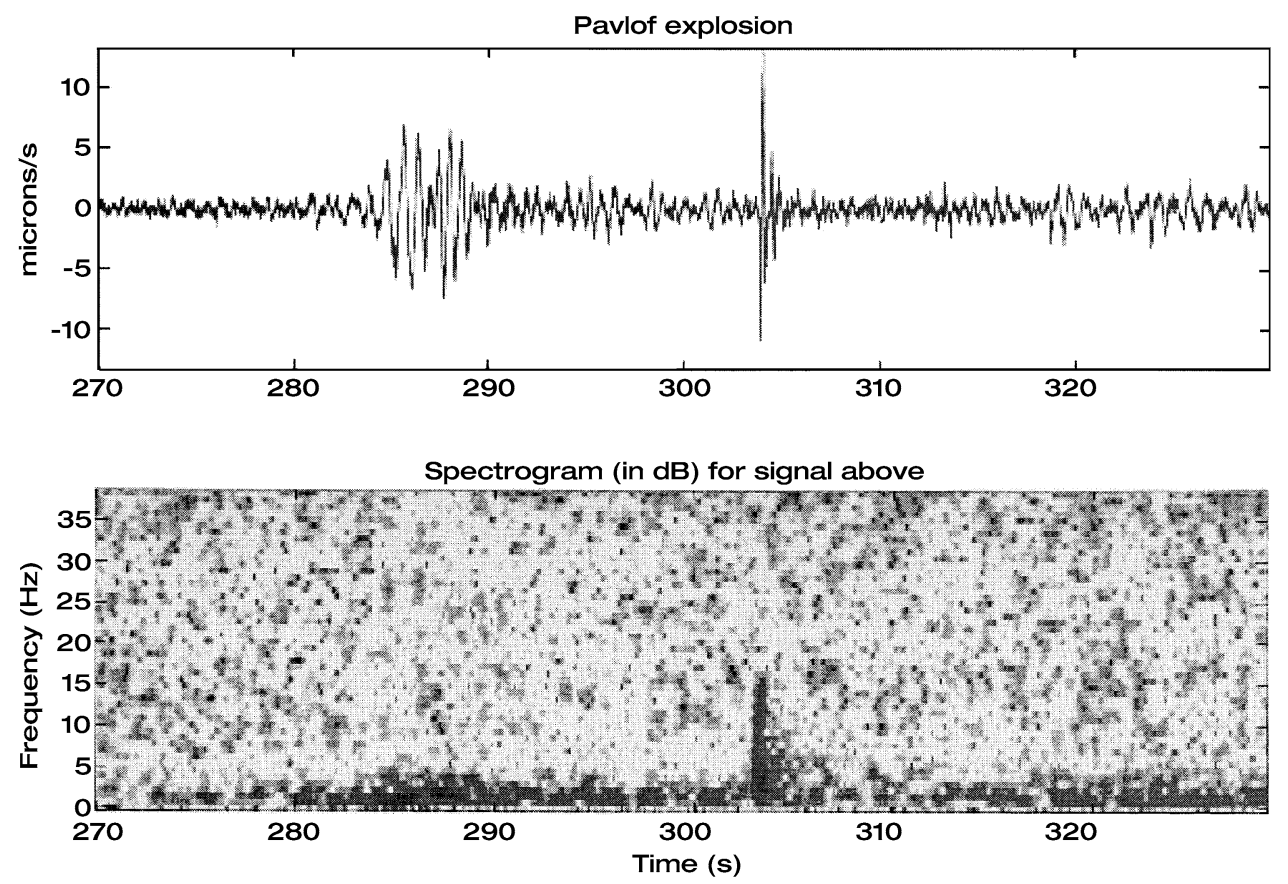

Fig. 12. Velocity waveform and spectrogram of an explosion signal with a low-frequency/high-frequency pair superposed on the background tremor, recorded during the 1996 eruption of Pavlof. The spectrogram was calculated using a sliding 1.28-s Hanning window with $90 \%$ overlap. Dark shades indicate high energy and light shades low energy (from Garcés and Hansen, 1998; ${ }^{\circ} \mathrm{AGU}$, reproduced with permission of American Geophysical Union).

Tremor signals accompanied by sounds observed in volcanoes that exhibit explosive degassing activity (Fig. 11) prompted researchers to investigate the possibility of a common link between the two phenomena. Even though it has been well known that volcanic eruptions can generate pressure disturbances in the atmosphere with a frequency that can range between $10^{-3}$ and $20 \mathrm{~Hz}$ (Richards, 1963), until recently there was no systematic recording of temporal variations of these signals near erupting volcanoes. Nowadays the installation of very sensitive microphones that record air-pressure waves with high resolution is an important supplement to the seismic monitoring of active volcanoes (Stromboli-Ripepe et al., 1996; Pavlof-Garcés and Hansen, 1998; ArenalGarcés et al., 1998; Sakurajima-Garcés et al., 1999; Karimsky/Sangay-Johnson and Lees, 2000; Mt. Erebus-Rowe et al., 2000). In the case of the Pavlof 1996 eruption, a common pattern of signals was observed consisting of pairs of short duration low-frequency/high-frequency phases on the seismograms superposed on the background tremor (Fig. 12), while at the same time explosion sounds were recorded by the microphones.

An explanation for the appearance of these two phases during explosion episodes has been given by Garcés and Hansen (1998) based on the concept of a stratified magma column (Fig. 13). This column is assumed to be composed of layers of magma with depth- and time-varying physical properties. While the deepest parts are dense and viscous, exhibiting high sound velocity, the shallower layers become less dense because of an increase in the bubble content owing to degassing that lowers their sound velocity. A steady flow of magma from a deeper reservoir is not expected to alter the stratification, therefore the deepest, dense layer acts as the area of generation of seismic waves (tremor) that, due to the sharp impedance contrast with the upper parts, can only propagate in the surrounding bedrock (low-frequency part). A similar process may occur in the shallower layer where metastable gas mixtures of $\mathrm{H}_{2} \mathrm{O}$ and $\mathrm{CO}_{2}$ 


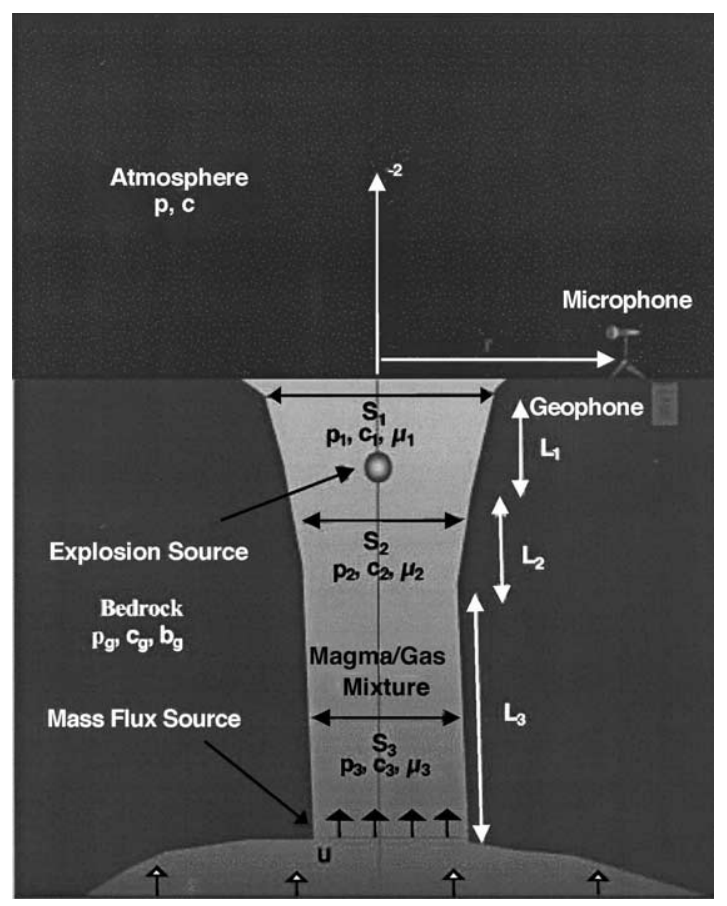

Fig. 13. A stratified magma column as it was modelled from seismoacoustic signals at Pavlof: $L_{3}=43 \mathrm{~m}, S_{3}=10 \mathrm{~m}^{2}$, $c_{3}=230 \mathrm{~m} / \mathrm{s}, \rho_{3}=2600 \mathrm{~kg} / \mathrm{m}^{3}, \mu_{3}=1 \times 10^{6} \mathrm{~Pa} \mathrm{~s} ; L_{2}=64 \mathrm{~m}$, $S_{2}=10 \mathrm{~m}^{2}, c_{2}=90 \mathrm{~m} / \mathrm{s}, \rho_{2}=2000 \mathrm{~kg} / \mathrm{m}^{3}, \mu_{2}=1.4 \times 10^{3} \mathrm{~Pa} \mathrm{~s}$; $L_{1}=15 \mathrm{~m}, \quad S_{1}=20 \mathrm{~m}^{2}, \quad c_{1}=51 \mathrm{~m} / \mathrm{s}, \quad \rho_{1}=1000 \mathrm{~kg} / \mathrm{m}^{3}$, $\mu_{1}=1.5 \times 10^{3} \mathrm{~Pa} \mathrm{~s}$; for the bedrock $\rho_{\mathrm{g}}=2700 \mathrm{~kg} / \mathrm{m}^{3}, c_{\mathrm{g}}=$ $3 \mathrm{~km} / \mathrm{s}$ and shear speed $b_{\mathrm{g}}=1.7 \mathrm{~km} / \mathrm{s}$; for the atmosphere $\rho=1 \mathrm{~kg} / \mathrm{m}^{3}, c=320 \mathrm{~km} / \mathrm{s}$. The mass flux source is considered to be responsible for the radiation of tremor signals, while the explosive source is generating signals like that shown in Fig. 12, see text for details (from Garcés and Hansen, 1998; Garcés et al., 2000; ${ }^{\circledR} \mathrm{AGU}$, reproduced with permission of American Geophysical Union).

can produce explosions that can only propagate in the atmosphere and then back to the ground (high-frequency air wave). On the other hand, an unstable, turbulent flow of magma can disrupt the stratification and smooth the density contrast between the layer boundaries so that it is possible to have sound waves propagating through the different parts of the magma column. Theoretical models of these processes have been published by Garcés (1997) and Garcés and McNutt (1997), while results from their direct application to model waveforms of seismoacoustic data acquired during the 1996 eruption of Pavlof volcano have been published by Garcés et al. (2000). Table 3 summa- rises visual as well as acoustic observations related to tremor activity reported at volcanoes around the world.

\section{Modelling the source of volcanic tremor}

\subsection{Fluid-flow-induced oscillations}

The process of how magma ascends from a deeper source and moves towards the surface causing an eruption has been studied extensively by many authors and at different scales. On the smallest possible scale magma is considered to flow through the porous matrix of partially molten rock, forming during its ascent shape-preserving (soliton) waves as has been demonstrated analytically (Scott and Stevenson, 1984) and experimentally (Scott and Stevenson, 1986). On a larger scale, the interior of a volcano is modelled as consisting of a shallow magma reservoir fed by a deeper source and a cylindrical-shaped conduit that transports the fluid upwards and may be connected to a network of other conduits (Fedotov, 1981). In general the reservoir is considered to behave elastically under variable stress conditions imposed by fluid accumulation or outflow. The cylindrical conduit on the other hand is believed to exhibit more complicated, viscous behaviour so that a high driving fluid pressure from below results in deformations transmitted periodically as expansions or contractions of its walls (Ida and Kumazawa, 1986; Ida, 1996). Elastic behaviour of the conduit may also be expected when the fluid pressure builds up quickly, forcing the conduit to respond elastically by a fast opening (Maeda, 2000).

Several observations made during eruptions suggest a direct link between inward and outward flow of magma from a reservoir and the generation of volcanic tremor. Tilt observations indicate the occurrence of cycles of slow build-up of ground deformation starting as volumetric expansion and terminating with contraction, being accompanied almost always by tremor episodes (Kilauea-Dvorak and Okamura, 1985; Izu OshimaOikawa et al., 1991; Fukao et al., 1998). The quantitative study of magma flow through a geo- 
metrically irregular volcanic conduit poses a difficult numerical problem which requires the formulation and simultaneous solution of a system of partial differential equations describing the flow of the fluid as well as the elastic disturbance being caused by the coupling to the surrounding rock (Chouet and Julian, 1985). Further complications may arise if the fluid consists of a gas and liquid phase, or if the thickness of the conduit changes in space as well as in time, effectively exhibiting viscous or visco-elastic behaviour. In models of tremor generation involving fluid flow, a number of simplifying assumptions are usually made: (a) the fluid has a constant density and consists of one phase only, (b) the motion occurs in one or two dimensions and (c) the conduit behaves elastically, while its thickness can only change as a function of time.

Based on these assumptions and using the principles of conservation of mass and momentum for the fluid, Julian (1994) derived a third-order system of non-linear ordinary differential equations that describe the flow inside a vertically extending crack connecting an upstream and a downstream reservoir (Fig. 14). Considering a fluid density and viscosity typical for basaltic melts $(\rho=2500$

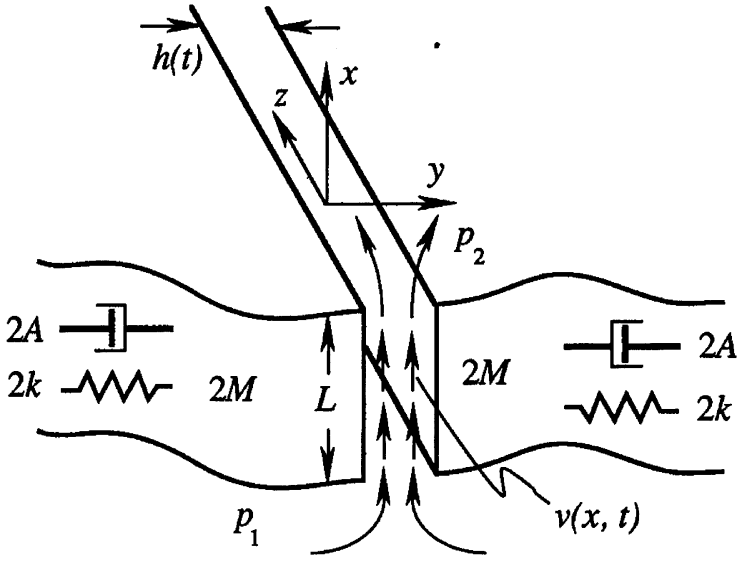

Fig. 14. Lumped parameter model of the generation of volcanic tremor. Viscous incompressible fluid flows in the $x$ direction from the upstream to downstream reservoir through a channel of length $(L)$ with imperfectly elastic walls, modelled as movable but undeformable blocks of mass $2 M$, stiffness $2 k$ and damping constant $2 A$ (all measured per unit distance in the $z$ direction). All motion occurs in the $x-y$ plane and it is independent of $z$. The dynamic variables are the channel thickness $h(t)$ and the fluid speed $v(x, t)$ (from Julian, 1994; reproduced with permission of American Geophysical Union)

Table 3

Reported visual and acoustic observations related to tremor activity

\begin{tabular}{lll}
\hline Region & Visual/acoustic observation & Reference \\
\hline Pavlof & Lava fountaining related to high-amplitude tremor & McNutt, 1986; Garcés and Hansen, 1998 \\
Klyutchevskoy & $\begin{array}{l}\text { Variation of tremor spectral amplitude envelope whenever the } \\
\text { eruptive activity changed }\end{array}$ & Gordeev et al., 1990
\end{tabular}

Kilauea Gas-piston events associated with cycles of ponding and withdrawal Ferrazzini and Aki, 1992 of lava from the crater followed by high-amplitude tremor

Mt. Semeru

Pumping and explosion sounds with durations of $40 \mathrm{~s}-16$ min that Schlindwein, 1994 coincided with tremor episodes

Stromboli Gas bursts at the top of the magma column coincide with highamplitude tremor

Arenal Different explosion sounds that are accompanied by ash plumes and precede tremor episodes

White Island Eruptive/intrusive activity always followed by inharmonic tremor

Satsuma-Iwojima Strong tremor occurring while vent emmits high-temperature volcanic gas

Karimsky/Sangay 'Chugging' tremor episodes followed by steam locomotive-like sounds

Ripepe et al., 1996; Ripepe, 1996

Benoit and McNutt, 1997; Garcés et al., 1998; Hagerty et al., 2000

Sherburn et al., 1998

Ohminato and Ereditato, 1998

Johnson and Lees, 2000 


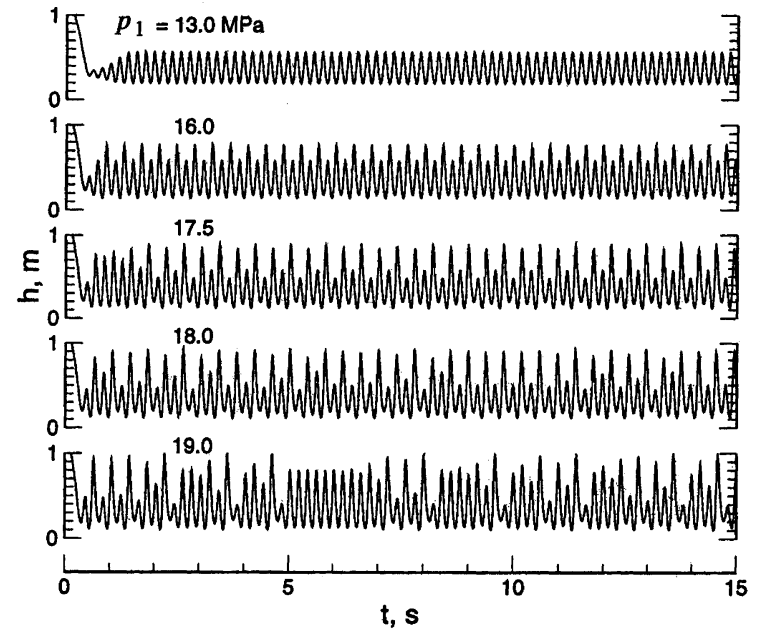

Fig. 15. Synthetic seismograms of volcanic tremor generated for different values of the magma driving pressure $p_{1}$ depicted in the flow model shown in Fig. 14. Note the gradual transition to the broadband trace for $p_{1}=19.0 \mathrm{MPa}$ (from Julian, 1994; reproduced with permission of American Geophysical Union).

$\mathrm{kg} \mathrm{m}^{-3}$ and $\eta=500 \mathrm{~Pa} \mathrm{~s}$ ), a crack $10 \mathrm{~m}$ long with a thickness (in equilibrium condition) of $1 \mathrm{~m}$, he solved the system of equations numerically for different values of driving pressure at the lower end of the conduit. In the interval $10-15 \mathrm{MPa}$ the numerical solutions indicate a cyclic behaviour of continuous increasing and decreasing conduit thickness. According to Bernoulli's theorem the quantity $p+\left(\rho v^{2}\right) / 2$ must remain constant, therefore for large flow speeds $v$ the fluid pressure $p$ in the conduit decreases and the walls move towards each other constricting the flow. For the same reason the pressure builds up again forcing the walls apart and resulting in a fluid-induced periodic oscillation. Oscillations for fluid pressure less than $10 \mathrm{MPa}$ were found to decay quickly in time, resembling to the behaviour of low-frequency earthquakes.

For fluid-pressure values greater than $15 \mathrm{MPa}$ a large number of subharmonics appears, assuming values that are $1 / 2,1 / 4,1 / 16, \ldots$ of the value of the fundamental period of the oscillation. This phenomenon, known as a 'period doubling cascade', is one of the ways that a system described by a set of non-linear differential equations may evolve from a periodic, predictable behaviour in the time/frequency domain to a state of non-periodic and almost noisy looking time series (Fig. 15), which is termed chaotic (e.g. Bergé et al., 1986). A plot of the triplet of values $h, v, \dot{h}$ (where $h$ is the conduit thickness and the dot indicates differentiation with respect to time), known as the state of the system, revealed sets of orbits that, while they diverge exponentially from each other due to sensitivity to initial conditions, also fold because of dissipation of energy (Fig. 16). This stretching and folding process makes them move always within a bounded region of the state space, forming a geometrical object with fractal properties, called a 'strange' attractor.

The question whether volcanic tremor generation may be controlled by a strange attractor was considered earlier by Chouet and Shaw (1991) and Shaw and Chouet (1991). Using methods from the discipline of non-linear dynamics they

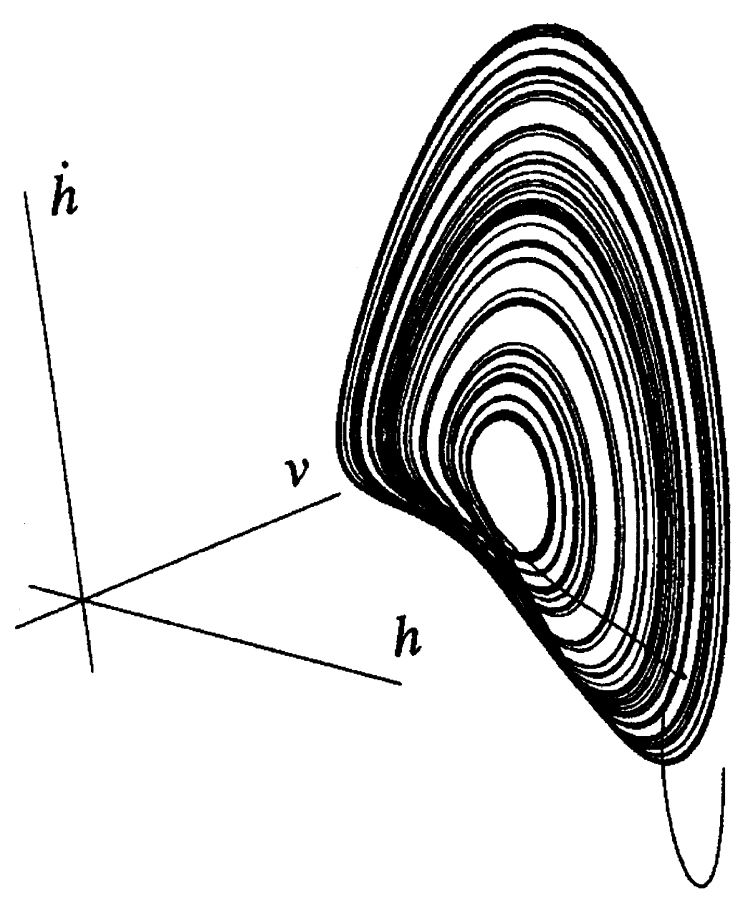

Fig. 16. Stereoscopic view of orbits in phase space formed by plotting the triplet of values $h, v, \dot{h}$ for a driving pressure of $p_{1}=19.0 \mathrm{MPa}$. The resulting geometrical object has a fractal structure and is called a 'strange' attractor. Note the folding of the orbits at the lower part of the plot (after Julian, 1994; modified with permission of American Geophysical Union). 
reconstructed the different states of the system from the original tremor seismograms recorded at Kilauea and found that such a fractal object exists within a bounded region of the state space. The fractal dimension $D_{\mathrm{f}}$ of a strange attractor is a non-integer number that describes its scaling properties, but also is a measure of the degrees of freedom of the studied system. The calculated value of $D_{\mathrm{f}}=3.6$ shows a low-dimensional behaviour $\left(D_{\mathrm{f}}<10\right)$ and led Chouet and Shaw (1991) to conclude that even though many processes may be at work (fluid flow, degassing) at different scales (flow through porous media or extended cracks), a small number of degrees of freedom is related to tremor generation. These results have been confirmed in subsequent studies of tremor time series recorded at different volcanoes (Mt. Etna-Godano et al., 1996; Stromboli-Godano and Capuano, 1999; Vatnajökull-Konstantinou, 2002) and point to the exciting possibility of a simple, low-dimensional representation for the physics of the tremor source. A description of the theory and methods of non-linear dynamics is beyond the scope of this review and the reader may further refer to specialised textbooks on the subject, e.g. Bergé et al. (1986) or Hilborn (1994).

Another type of flow-induced oscillation may occur if the fluid system is suddenly perturbed from its equilibrium state by some external cause, like fracturing of the surrounding bedrock and formation of a new conduit, or a sudden variation in the fluid supply (St Lawrence and Qamar, 1979; Ferrick et al., 1982). This will result in the generation of a fluid transient with characteristics that will depend on the physical properties of the fluid, the geometry of the conduit and the boundary conditions. Pressure oscillations caused by the transient will displace the conduit walls generating elastic waves in the surrounding medium. Two parameters that control the frequency response of the system are the characteristic impedance of the fluid $Z_{\mathrm{c}}$ and the orifice impedance $Z_{\mathrm{or}}$, defined as:

$$
Z_{\mathrm{c}}=\frac{a}{g A}, Z_{\mathrm{or}}=\frac{2 H}{Q}
$$

where $a$ is the pressure wave speed in the fluid, $g$ is the acceleration due to gravity, $A$ is the cross- sectional area of the conduit, $H$ is the pressure head and $Q$ is the flow rate of the fluid. $Z_{\text {or }}>Z_{\mathrm{c}}$ means a small conduit opening, where a small quantity of fluid passing through resembles a closed-pipe system, with frequencies $\omega=n \pi a / 2 L$, where $L$ is the conduit length and $n=1,3,5, \ldots$. For $Z_{\mathrm{or}}<Z_{\mathrm{c}}$ the inverse is true and the system responds as an open pipe with frequencies given by the same equation but $n=2,4,6, \ldots$. More complicated behaviour is expected if the conduit is a part of an extended network such as is believed to exist beneath many volcanoes. Energy considerations show that once the system is perturbed it will continue to oscillate, until damped primarily by fluid friction, since dissipation of energy due to the generation of seismic waves is relatively small (Ferrick and St. Lawrence, 1984). Similar unsteady flow in conduits followed by tremor-like seismic signals has been reported at a power plant at Oroville, California caused by a faulty valve and at Tarbela dam, Pakistan, while water was moving through outflow tunnels (McNutt, 1986).

\subsection{Excitation of fluid-filled cracks}

Brittle failure of rock and crack formation inevitably accompany any upward movement of magma during different stages of volcanic activity. The main result of such rock fracturing is the generation of various types of seismic signals, ranging from events that can hardly be distinguished from common tectonic earthquakes to low-frequency events with emergent onsets, absence of clear S-wave phases and a slowly decaying coda (Chouet, 1996). Injection of water into hot dry rock has been found to produce seismic signals similar to low-frequency volcanic earthquakes and supports the idea of a source that involves the opening of tensile cracks caused by excess fluid pressure (Bame and Fehler, 1986). The overall similarity of tremor and low-frequency events in the time and frequency domains, notwithstanding their different signal duration, has been pointed out by many authors as indicating that a common source may be at work, and which of the two seismic signals will be generated depends on the duration of the excitation mechanism (Fehler, 1983; Chouet, 1985; Hofstetter and 
Malone, 1986; Tsuruga et al., 1997; Almendros et al., 1997).

Volcanic tremor underneath Kilauea during the 1963 eruption was mainly composed of $P$ waves, shared the same source area with the low-frequency earthquakes and was deep enough to assume that its source had to do with magma transportation rather than degassing processes (Aki et al., 1977; Aki and Koyanagi, 1981). Aki et al. (1977) proposed that the observed tremor could be explained by the jerky extension of a chain of cracks caused by magmatic pressure build-up as magma moves away from a deep reservoir beneath the summit of the volcano. The cracks may be placed in a series and are connected by narrow channels that open when magma pressure reaches a critical value, facilitating the movement of fluid from one crack to the next one. The vibration caused by such a movement was found to have a period proportional to the crack length and an amplitude that depended on the excess pressure and the area of extension. In order to explain the temporal variations of the frequency content during a tremor episode from higher (5$10 \mathrm{~Hz})$ to lower frequencies $(1.5-3 \mathrm{~Hz})$, Aki and Koyanagi (1981) suggested that this process starts with a few cracks generating a signal of small period which increases as more cracks vibrate and the length of the chain gets longer. However, two discrepancies have been pointed out regarding this model; first, as the length of the chain is increasing, this should lead to systematic lowering of the frequencies of the tremor signal, which was not observed. Second, numerical studies on crack generation and growth show that a tensile stress regime combined with the fact that the largest part of each crack is expected to be filled with fluid, favour catastrophic growth rather than a stable opening-closing process (Sammis and Julian, 1987).

Chouet (1986, 1988) considered the displacement of the walls of a fluid-filled crack (Fig. 17) caused by a pressure disturbance in the fluid as a possible model for the generation of low-frequency earthquakes, as well as tremor, if the disturbance is sustained. This model is qualitatively different from that proposed by Aki et al. (1977), since it assumes the vibration of only one crack

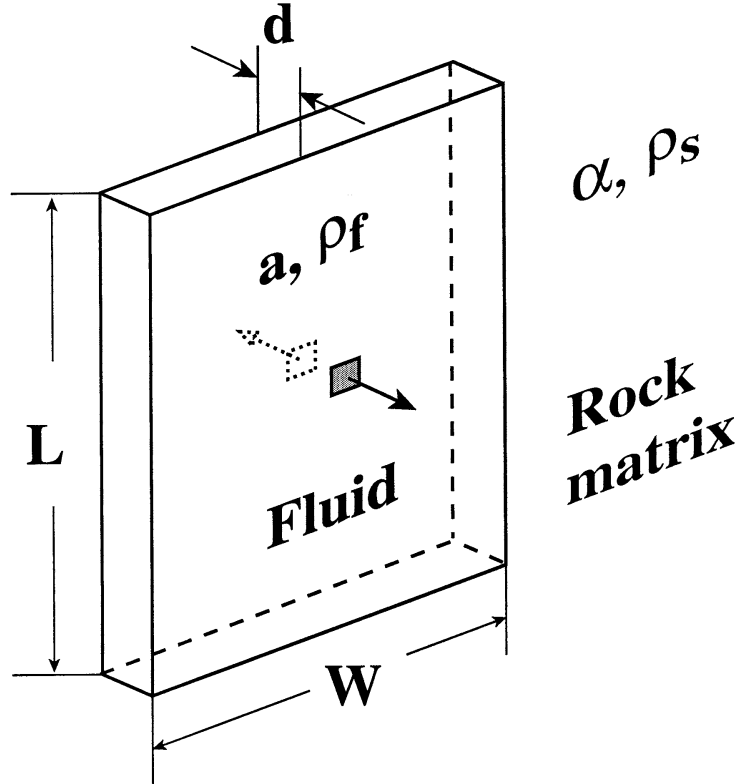

Fig. 17. Geometry of the fluid-filled crack model described by Chouet (1986, 1988); see text for more details. The shaded area indicates the place of application of the pressure transient that triggers resonance (B.A. Chouet, pers. comm., 2001)

with no inflow or outflow of fluid taking place. The characteristics of the far-field wavefield radiated by a rectangular shaped vibrating crack, filled with an inviscid fluid and assuming that the surrounding bedrock behaves as a Poisson solid, were found to depend on the following parameters: (a) the crack geometry; (b) the position and the area over which the pressure disturbance occurs; (c) boundary conditions for the stress on the crack's surface and the fluid flow at the crack perimeter; and (d) a dimensionless quantity called the crack stiffness $C$ and the fluid-solid impedance contrast $Z$, defined as:

$C=\frac{b L}{\mu d}, Z=\frac{\rho_{\mathrm{s}} \alpha}{\rho_{\mathrm{f}} a}$

where $b$ is the bulk modulus of the fluid, $\mu$ is the rigidity of the solid, $L$ is the crack length, $d$ is the crack thickness, $\rho_{\mathrm{s}}$ is the density of the solid with $\alpha$ its P-wave velocity and $\rho_{\mathrm{f}}$ the density of the fluid with P-wave velocity equal to $a$. For many different combinations of the above parameters 
the fluid-filled crack model was found to have longitudinal and lateral modes of oscillation that are given by $2 L / n$ and $2 W / n$, where $n=2,3,4, \ldots$ with $L$ and $W$ the length and width of the rectangular crack. The spectrum of the far-field radiated waves is dominated by sharp peaks representing the mixing of the longitudinal and lateral modes of the resonating crack (Fig. 18). Laboratory simulations of different kinds of gas-liquid flows inside a vertically mounted tube (Lane et al., 2001) were found to exhibit pressure oscillations consistent with the oscillation modes described by Chouet's model. Furthermore Morrissey and Chouet (1997) investigated the dynamics of the formation of shock waves downstream from a nozzle-like constriction ('choked' flow) inside a crack as a possible physical mechanism for crack resonance. Their theoretical calculations showed that unsteady shock waves near the crack walls may generate pressure transients responsible for inducing resonance of the fluid-filled crack.

The fundamental period of resonance for the crack was found by Chouet (1988) to be much longer than the expected one due to the existence of a slow wave propagating along the fluid-solid boundary, which he called a 'crack wave'. This kind of wave exhibits inverse dispersive properties in the sense that both group and phase velocities tend to zero with increasing wavelengths and/or increasing crack stiffness. After numerical calculations Ferrazzini and Aki (1987) found that a fluidfilled crack with $1 \mathrm{~km}$ length, $0.5 \mathrm{~m}$ thickness, density ratio of $\rho_{\mathrm{s}} / \rho_{\mathrm{f}}=2.5$ and velocity ratio of $\alpha / a=1.5$ will have a resonance period of $10 \mathrm{~s}$. They further suggest that this gives a geologically more reasonable explanation for the observation of 10-s-period tremor at Mt. Aso first made by Sassa (1936) than the oscillations of a magma chamber with a diameter of 4-8 km.

The calculated quality factor $Q$ of the vibrating fluid-filled crack, whereas reached a maximum value of 20 for an impedance contrast equal to 40 , showed a substantial difference to the values of $Q=40$ reported by Ferrazzini and Aki (1992) for Hawaiian tremor. Initially Chouet (1992) attributed this difference on two reasons: first, the model considers a fluid consisting of one phase only, while in reality some percentage of gas bub-
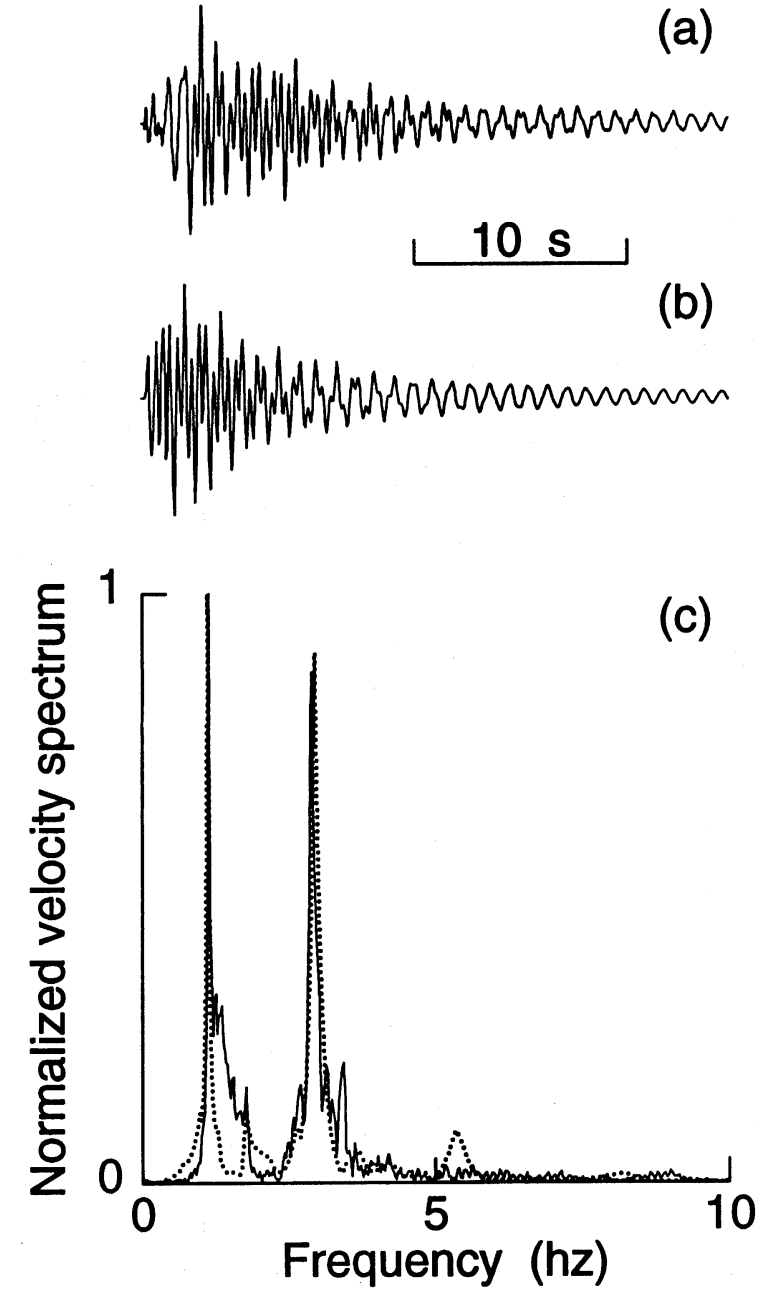

Fig. 18. Example of the application of the fluid-filled crack model shown in Fig. 17 for an event recorded at Galeras volcano, Colombia. (a) Vertical velocity waveform. (b) Synthetic waveform generated by the model for a crack length $180 \mathrm{~m}$, crack width $90 \mathrm{~m}$, crack aperture $0.05 \mathrm{~m}$, crack stiffness 100 , sound speed of fluid $0.3 \mathrm{~km} \mathrm{~s}^{-1}$, compressional wavespeed of solid $2.5 \mathrm{~km} \mathrm{~s}^{-1}$, density ratio of fluid to rock 0.5 , ratio of bulk modulus of fluid to rigidity of rock 0.025 . (c) Spectrum for data (thin line) and synthetics (dotted line) (from Chouet, 1996; reproduced with permission of Nature magazine).

bles should be present, even though this factor restricts the applicability of the model only to shallow tremor. Second, it is highly unlikely that the recorded tremor is the result of only one fluidfilled crack and the mixing of waves radiated by many resonating cracks may have created the ob- 
served difference. Subsequent calculations of the quality factor using two-phase fluids (assuming also that the gas phase contains small size particles) published by Kumagai and Chouet (2000) are in the range of 1 to several hundred, reconciling the theoretical results with the observed $Q$ values.

\subsection{Hydrothermal boiling}

The fact that the formation of bubbles in a liquid is an efficient way of seismic energy generation has long been recognised and utilised in exploration geophysics (Dobrin and Savit, 1986). Geysers and geothermal reservoirs are natural sources of such seismic energy and seismological studies at the Old Faithful geyser revealed the existence of tremor-like signals related to boiling of groundwater (Kieffer, 1984; Kedar et al., 1996). Leet (1988) suggested that processes similar to the ones observed at Old Faithful could be used to explain the generation of volcanic tremor recorded during quiet periods at certain volcanoes, which he called 'non-eruption tremor'. Two restrictions regarding this model are: (a) the magma chamber underneath the volcano acting as the source of heat should not reside at a higher elevation level than the groundwater table; and (b) the process should operate at shallow depths, so that steam can be separated from the liquid. Obviously, hydrothermal boiling cannot explain tremor processes operating at depths larger than a few kilometres from the Earth's surface.

Boiling of groundwater causes the formation and growth of bubbles in the liquid that may collapse if they encounter a liquid region of lower temperature. Either of these two mechanisms can generate seismic energy, but Leet (1988) found that bubble collapse is $10^{2}-10^{4}$ times more efficient in converting thermal power to seismic power; the boiling heat transfer rates in order for bubble collapse to generate $1-\mathrm{Hz}$ tremor should be about $1000 \mathrm{MW}$, which he notes is the upper limit of observed heat flow in volcanic crater lakes and geothermal areas. The resulting signal is expected to resemble white noise, with equal energy in all frequency bands, which is in contrast to the sharply peaked tremor spectra.
However, assuming that the groundwater is contained in a channel the boiling process may set it into resonance, so that the frequency response of the channel will be convolved with the broadband noise. The length of the channel needed to generate a signal with frequencies in the range $0.5-5 \mathrm{~Hz}$ is given by $L=a / 2 f$, where $a$ is the sound velocity of the liquid taking values of $50-1500 \mathrm{~m} / \mathrm{s}$ for groundwater and therefore $L$ is in the range $1-1000 \mathrm{~m}$.

\subsection{Resonance of large magma bodies}

Among the first models to be used in order to explain the occurrence of volcanic tremor is that of the free oscillations of magma bodies of various shapes. For example Sassa (1936) and later Shima (1958) and Kubotera (1974) suggested that the observed 10-s-period tremor at Mt. Aso was caused by the oscillation of a spherical magma chamber beneath the volcano. However a simple calculation of the radius $(r)$ of the chamber using the equation $f=4.4 a / 2 \pi r$, where $a$ is the sound velocity of the melt taking a value of $1-2 \mathrm{~km} / \mathrm{s}$ and $f$ the frequency of oscillation, yields a radius value of $7-14 \mathrm{~km}$. Furthermore no exact physical mechanism which could set the whole chamber into oscillation was identified.

Assuming that the low-frequency earthquakes may be a kind of impulse response of the tremor-generating system, Chouet (1985) proposed a model to explain such earthquakes by studying the oscillations of a buried magmatic pipe. The pipe consisted of three parts: on the top a hemispherical cavity filled with gas was considered to be triggering the oscillations due to excess gas pressure, in the middle the resonating pipe had a cylidrical shape and was filled with magma, and at the bottom it was shut by a horizontal disk. The calculated free surface response of this system showed an impulsive signature in the vicinity of the pipe, but evolved to a harmonic wavetrain at larger distances. In the frequency domain the system exhibited sharp peaks corresponding to the well-known organ-pipe modes with amplitudes that depend on the amount of energy loss due to viscous damping in the fluid and radiation of seismic energy in the solid. 
Based on similar ideas about the relationship of tremor and low-frequency earthquakes, Crosson and Bame (1985) studied the resonance of a magma filled spherical cavity encased in country rock which contained a smaller cavity filled with gas. The motivation for such a model also came from observations at Stromboli, where low-frequency earthquakes were found to originate a few seconds prior to explosions. In that sense expansion of the gas-filled cavity could set the magma-filled one into resonance ('breathing mode'). The signal generated by such an oscillation had a frequency content of $1-5 \mathrm{~Hz}$, consistent with the observations, and an impulsive signature in the time domain. Again it was assumed that sustained expansions of the gas-filled pocket (probably due to pressure variations) would give rise to continuous tremor.

\section{Concluding remarks}

It is clear from the description presented above that, even though current research on volcanic tremor covers a wide range of concepts and tools, this does not alter the fact that tremor still remains a poorly understood phenomenon. An enhanced understanding of it through future research efforts may critically depend on three basic factors:

Proper instrumentation and data quality: Several observations of tremor with a frequency content in the range $0.1-0.3 \mathrm{~Hz}$ or lower, discussed previously in this review, point to the necessity of seismic monitoring of volcanoes with broadband instruments. Also, the successful application of methods to locate the tremor source by utilising wavefield properties depends on an adequate number of three-component seismometers. An often-overlooked aspect of data acquisition is the sampling interval used, since certain methods, e.g. those for the estimation of the correlation dimension of a strange attractor, need a sufficient amount of samples in order to be applied successfully (e.g. Chouet and Shaw, 1991). Additional recordings of acoustic data require the installation of sensitive microphones while visual observations in many cases involve the use of video cameras for the continuous monitoring of the state of activity near the volcano (e.g. Ripepe et al., 1996).

A multidisciplinary approach: Having to deal with a signal that is generated by the interactions of heterogeneous materials with time- and spacevarying properties means that seismic data alone cannot provide adequate constrains when modelling the tremor source. A combination of seismic, acoustic and visual observations is essential for the recovery of information about the physical properties and the geometry of the magma column as has been demonstrated by Garcés et al. (2000). This combination implies a multidisciplinary approach in the study of volcanoseismic signals that involves not only physical volcanology and seismology but also fluid dynamics and theoretical acoustics.

More elaborate modelling: As computer power and speed constantly improve, it may be possible to numerically simulate complicated fluid flow models like von Kármàn vortices or turbulent slug flow of magma/hydrothermal fluids (e.g. Hellweg, 2000) and consider the coupling of these disturbances to the conduit walls.

\section{Acknowledgements}

We would like to thank Steve Sherburn, Milton Garcés, Bernard Chouet, Phil Dawson and Tim Bond for providing the original figures that appear in this paper. Neil Goulty and Christine Peirce carefully reviewed the original manuscript and suggested many improvements. Lionel Wilson was the editor responsible for handling the paper and kindly helped us to improve it.

\section{References}

Aki, K., 1957. Space and time spectra of stationary stochastic waves, with special reference to microtremors. Bull. Earthq. Res. Inst. Tokyo Univ. 25, 415-457.

Aki, K., 1959. Correlational study of near earthquakes waves. Bull. Earthq. Res. Inst. Tokyo Univ. 37, 207-232.

Aki, K., 1992. State of the art in volcanic seismology. In: Gasparini, P., Scarpa, R., Aki, K. (Eds.), Volcanic Seismology. IAVCEI Proc. Volcanol. 3, 3-10.

Aki, K., Koyanagi, R.Y., 1981. Deep volcanic tremor and 
magma ascent mechanism under Kilauea, Hawaii. J. Geophys. Res. 86, 7095-7110.

Aki, K., Fehler, M., Das, S., 1977. Source mechanism of volcanic tremor: fluid-driven crack models and their application to the 1963 Kilauea eruption. J. Volcanol. Geotherm. Res. 2, 259-287.

Almendros, J., Ibanez, J.M., Alguacil, G., Del Pezzo, E., Ortiz, R., 1997. Array tracking of the volcanic tremor source at Deception Island, Antarctica. Geophys. Res. Lett. 24, 30693072.

Almendros, J., Chouet, B.A., Dawson, P., Bond, T., 2002. Identifying elements of the plumbing system beneath $\mathrm{Ki}$ lauea Volcano, Hawaii, from the source location of very long period signals. Geophys. J. Int. 148, 303-312.

Anstey, N.A., 1981. Seismic Prospecting Instruments, Vol. 1: Signal Characteristics and Instrument Specifications. Gebr. Bornträger, Berlin.

Bame, D., Fehler, M., 1986. Observations of long-period earthquakes accompanying hydraulic fracturing. Geophys. Res. Lett. 13, 149-152.

Båth, M., 1974. Spectral Analysis in Geophysics. Elsevier, Amsterdam, $563 \mathrm{pp}$.

Benoit, J., McNutt, S.R., 1997. New constraints on the source processes of volcanic tremor at Arenal volcano, Costa Rica, using broadband seismic data. Geophys. Res. Lett. 24, 449452.

Bergé, P., Pomeau, Y., Vidal, C., 1986. Order Within Chaos: Towards a Deterministic Approach to Turbulence. Wiley, New York, 265 pp.

Bond, T., 2000. A Study of Very Long Period Seismicity at Kilauea Volcano, Hawaii. MSc Thesis, University of Durham, Durham, 101 pp.

Brandsdóttir, B., Einarsson, P., 1992. Volcanic tremor and low-frequency earthquakes in Iceland. In: Gasparini, P., Scarpa, R., Aki, K. (Eds.), Volcanic Seismology. IAVCEI Proc. Volcanol. 3, 212-222.

Burg, J.P., 1967. Maximum entropy spectral analysis. In: Childers (Ed.), Modern Spectral Analysis. IEEE Press, New York, pp. 34-41.

Chouet, B.A., 1985. Excitation of a buried magmatic pipe: A seismic source model for volcanic tremor. J. Geophys. Res. 90, 1881-1893.

Chouet, B.A., 1986. Dynamics of a fluid-driven crack in three dimensions by the finite difference method. J. Geophys. Res. 91, 967-992.

Chouet, B.A., 1988. Resonance of a fluid-driven crack: radiation properties and implications for the source of long-period events and harmonic tremor. J. Geophys. Res. 93, 43754400.

Chouet, B.A., 1992. A seismic model for the source of longperiod events and harmonic tremor. In: Gasparini, P., Scarpa, R., Aki, K. (Eds.), Volcanic Seismology. IAVCEI Proc. Volcanol. 3, 133-156.

Chouet, B.A., 1996. Long-period volcano seismicity: its source and use in eruption forecasting. Nature 380, 309-316.

Chouet, B.A., Julian, B.R., 1985. Dynamic of an expanding fluid-filled crack. J. Geophys. Res. 90, 11187-11198.
Chouet, B.A., Shaw, H.R., 1991. Fractal properties of tremor and gas piston events observed at Kilauea volcano. J. Geophys. Res. 96, 10177-10189.

Chouet, B.A., De Luca, G., Milana, G., Dawson, P., Martini, M., Scarpa, R., 1998. Shallow velocity structure of Stromboli volcano, Italy, derived from small aperture array measurements of Strombolian tremor. Bull. Seismol. Soc. Am. 88, 653-666.

Chouet, B.A., Saccaroti, G., Dawson, P., Martini, M., Scarpa, R., DeLuca, G., Milana, G., Cattaneo, M., 1999. Broadband measurements of the sources of explosions at Stromboli volcano, Italy. Geophys. Res. Lett. 26, 19371940.

Crosson, R.S., Bame, D.A., 1985. A spherical source model for low frequency volcanic earthquakes. J. Geophys. Res. 90, 10237-10247.

Dobrin, M., Savit, C., 1986. Introduction to Geophysical Prospecting. Wiley, New York, 796 pp.

Dvorak, J.J., Okamura, A.T., 1985. Variations in tilt rate and harmonic tremor amplitude during the January-August 1983 East Rift eruptions of Kilauea volcano, Hawaii. J. Volcanol. Geotherm. Res. 25, 249-258.

Ereditato, D., Luongo, G., 1994. Volcanic tremor wavefield during quiescent and eruptive activity at Mt. Etna (Sicily). J. Volcanol. Geotherm. Res. 61, 239-251.

Fedotov, S.A., 1981. Magma rates in feeding conduits of different volcanic centres. J. Volcanol. Geotherm. Res. 9, 379 394.

Fehler, M.C., 1983. Observations of volcanic tremor at Mt. St Helens volcano. J. Geophys. Res. 88, 3476-3484.

Ferrazzini, V., Aki, K., 1987. Slow waves trapped in a fluidfilled infinite crack: implication for volcanic tremor. J. Geophys. Res. 92, 9215-9223.

Ferrazzini, V., Aki, K., 1992. Preliminary results from a field experiment on volcanic events at Kilauea using an array of digital seismographs. In: Gasparini, P., Scarpa, R., Aki, K. (Eds.), Volcanic Seismology. IAVCEI Proc. Volcanol. 3, 168-189.

Ferrazzini, V., Aki, K., Chouet, B., 1991. Characteristics of seismic waves composing Hawaiian volcanic tremor and gas-piston events observed by a near source array. J. Geophys. Res. 96, 6199-6209.

Ferrick, M.G., St. Lawrence, W.F., 1984. Comment on 'Observations of volcanic tremor at Mt. St Helens volcano' by Michael Fehler. J. Geophys. Res. 89, 6349-6350.

Ferrick, M.G., Qamar, A., St. Lawrence, W.F., 1982. Source mechanism of volcanic tremor. J. Geophys. Res. 87, 86758683

Ferrucci, F., Godano, C., Pino, N.A., 1990. Approach to the volcanic tremor by covariance analysis: Application to the 1989 eruption of Mt Etna (Sicily). Geophys. Res. Lett. 17, 2425-2428.

Fukao, Y., Fujita, E., Hori, S., Kanjo, K., 1998. Response of a volcanic conduit to step-like change in magma pressure. Geophys. Res. Lett. 25, 105-108.

Furumoto, M., Kunimoto, T., Inoue, H., Yamada, I., Yamaoka, K., Akami, A., Fukao, Y., 1990. Twin sources of high- 
frequency volcanic tremor of Izu-Oshima volcano, Japan. Geophys. Res. Lett. 17, 25-27.

Furumoto, M., Kunimoto, T., Inoue, H., Yamaoka, K., 1992. Seismic image of the volcanic tremor source at Izu-Oshima volcano, Japan. In: Gasparini, P., Scarpa, R., Aki, K. (Eds.), Volcanic Seismology. IAVCEI Proc. Volcanol. 3, 201-211.

Garcés, M.A., 1997. On the volcanic waveguide. J. Geophys. Res. 102, 22547-22564.

Garcés, M.A., Hansen, R.A., 1998. Waveform analysis of seismoacoustic signals radiated during the Fall 1996 eruption at Pavlof volcano, Alaska. Geophys. Res. Lett. 25, 10511054.

Garcés, M.A., McNutt, S.R., 1997. Theory of the airborne sound field generated in a resonant magma conduit. J. Volcanol. Geotherm. Res. 78, 155-178.

Garcés, M.A., Hagerty, M.T., Schwartz, S.Y., 1998. Magma acoustics and time-varying melt properties at Arenal volcano, Costa Rica. Geophys. Res. Lett. 25, 2293-2296.

Garcés, M.A., Iguchi, M., Ishihara, K., Morrisey, M., Sudo, Y., Tsutsui, T., 1999. Infrasonic precursors to a vulcanian eruption at Sakurajima volcano, Japan. Geophys. Res. Lett. 26, 2537-2540.

Garcés, M.A., McNutt, S.R., Hansen, R.A., Eichelberger, J.C., 2000. Application of wave-theoretical models to the interpretation of explosion and eruption tremor signals radiated by Pavlof volcano, Alaska. J. Geophys. Res. 105, 30393058.

Godano, C., Capuano, P., 1999. Source characterisation of low frequency events at Stromboli and Vulcano islands (Isole Eolie Italy). J. Seismol. 3, 393-408.

Godano, C., Cardaci, C., Privitera, E., 1996. Intermittent behaviour of volcanic tremor at Mt. Etna. Pure Appl. Geophys. 147, 730-743.

Goldstein, P., Chouet, B., 1994. Array measurements and modelling of sources of shallow volcanic tremor at Kilauea volcano, Hawaii. J. Geophys. Res. 99, 2637-2652.

Gordeev, E.I., Saltykov, V.A., Synitsin, V.I., Chebrov, V.N., 1990. Temporal and spatial characteristics of volcanic tremor wavefields. J. Volcanol. Geotherm. Res. 40, 89-101.

Gottschämmer, E., Surono, I., 2000. Locating tremor and shock sources recorded at Bromo volcano. J. Volcanol. Geotherm. Res. 101, 199-209.

Hagerty, M.T., Schwartz, S.Y., Garcés, M.A., Protti, M., 2000. Analysis of seismic and acoustic observations at Arenal volcano, Costa Rica, 1995-1997. J. Volcanol. Geotherm. Res. 101, 27-65.

Hellweg, M., 1999. Seismic signals from Lascar volcano. J. South Am. Earth Sci. 12, 123-133.

Hellweg, M., 2000. Physical models for the source of Lascar's harmonic tremor. J. Volcanol. Geotherm. Res. 101, 183-198.

Hilborn, R.C., 1994. Chaos and Nonlinear Dynamics: An Introduction for Scientists and Engineers. Oxford University Press, Oxford, $672 \mathrm{pp}$.

Hofstetter, A.S., Malone, S.D., 1986. Observations of volcanic tremor at Mt. St Helens in April and May 1980. Bull. Seismol. Soc. Am. 76, 923-938.
Hurst, A.W., 1985. A volcanic tremor monitoring system. J. Volcanol. Geotherm. Res. 26, 181-187.

Hurst, A.W., 1992. Stochastic simulation of volcanic tremor from Ruapehu. J. Volcanol. Geotherm. Res. 51, 185-198.

Ida, Y., 1996. Cyclic fluid effusion accompanied by pressure change: implication for volcanic eruptions and tremor. Geophys. Res. Lett. 23, 1457-1460.

Ida, Y., Kumazawa, M., 1986. Ascent of magma in a deformable vent. J. Geophys. Res. 91, 9297-9301.

Johnson, J.B., Lees, J.M., 2000. Plugs and chugs - seismic and acoustic observations of degassing explosions at Karimsky, Russia and Sangay. Ecuador. J. Volcanol. Geotherm. Res. 101, 67-82.

Julian, B.R., 1994. Volcanic tremor: Nonlinear excitation by fluid flow. J. Geophys. Res. 99, 11859-11877.

Jurkevics, A., 1988. Polarisation analysis of three-component array data. Bull. Seismol. Soc. Am. 78, 1725-1743.

Kawakatsu, H., Ohminato, T., Ito, H., 1994. 10 s period volcanic tremors observed over a wide area in south-western Japan. Geophys. Res. Lett. 21, 1963-1966.

Kawakatsu, H., Kaneshima, S., Matsubayashi, H., Ohminato, T., Sudo, Y., Tsutsui, T., Uhira, K., Yamasato, H., Legrand, D., 2000. Aso94: Aso seismic observation with broadband instruments. J. Volcanol. Geotherm. Res. 101, $129-154$.

Kedar, S., Sturtevant, B., Kanamori, H., 1996. The origin of harmonic tremor at Old Faithful geyser. Nature 379, 708711 .

Kieffer, S.W., 1984. Seismicity at Old Faithful geyser: An isolated source of geothermal noise and possible analogue of volcanic seismicity. J. Volcanol. Geotherm. Res. 22, 5995.

Konstantinou, K.I., 2002. Deterministic nonlinear source processes of volcanic tremor signals accompanying the 1996 Vatnajökull eruption, central Iceland. Geophys. J. Int. 148, 664-667.

Konstantinou, K.I., Nolet, G., Morgan, W.J., Allen, R.M., Pritchard, M.J., 2000. Seismic phenomena associated with the 1996 Vatnajökull eruption, central Iceland. J. Volcanol. Geotherm. Res. 102, 169-187.

Kubotera, A., 1974. Volcanic tremors at Aso volcano. In: Civetta, L., Gasparini, P., Luongo, G., Rapolla, A. (Eds.), Physical Volcanology. Elsevier, Amsterdam, pp. 29-48.

Kumagai, H., Chouet, B.A., 2000. Acoustic properties of a crack containing magmatic or hydrothermal fluids. J. Geophys. Res. 105, 25493-25512.

Lane, S.J., Chouet, B.A., Philips, J.C., Dawson, P., Ryan, G.A., Hurst, E., 2001. Experimental observations and flow regimes in an analogue volcanic system. J. Geophys. Res. 106, 6461-6476.

Latter, J., 1979. Volcanological observations at Tongariro national park. 2: Types and classification of volcanic earthquakes 1976-1978. Geophysics Division Report 150, Dept. Sci. Ind. Res.

Lay, T., Wallace, T.C., 1995. Modern Global Seismology. Academic Press, New York, 521 pp.

Leet, R.C., 1988. Saturated and subcooled hydrothermal boil- 
ing in groundwater flow channels as a source of harmonic tremor. J. Geophys. Res. 93, 4835-4849.

Maeda, I., 2000. Nonlinear visco-elastic volcanic model and its application to the recent eruption of Mt Unzen. J. Volcanol. Geotherm. Res. 95, 35-47.

McNutt, S.R., 1986. Observations and analysis of B-type earthquakes, explosions and volcanic tremor at Pavlof volcano, Alaska. Bull. Seismol. Soc. Am. 76, 153-175.

McNutt, S.R., 1996. Seismic monitoring and eruption forecasting of volcanoes: A review of the state-of-the-art and case histories. In: Scarpa, Tilling (Eds.), Monitoring and Mitigation of Volcanic Hazards. Springer, Berlin, pp. 100146.

Métaxian, J.P., Lesage, P., Dorel, J., 1997. Permanent tremor of Masaya volcano, Nicaragua: Wave field analysis and source location. J. Geophys. Res. 102, 22529-22545.

Minakami, T., 1960. Fundamental research for predicting volcanic eruptions (Part 1). Bull. Earthq. Res. Inst. Univ. Tokyo 38, 497-544.

Montalbetti, J.F., Kanasewich, K.R., 1970. Enhancement of teleseismic body phases with a polarisation filter. Geophys. J. R. Astron. Soc. 21, 119-129.

Morrissey, M.M., Chouet, B.A., 1997. A numerical investigation of choked flow dynamics and its application to the triggering mechanism of long-period events at Redoubt volcano, Alaska. J. Geophys. Res. 102, 7965-7983.

Neidel, N., Tanner, M.T., 1971. Semblance and other coherency measure for multichannel data. Geophysics 36, 483497.

Nishimura, T., Hamaguchi, H., Ueki, S., 1995. Source mechanisms of volcanic tremor and low-frequency earthquakes associated with the 1988-89 eruptive activity of Mt Tokachi, Hokkaido, Japan. Geophys. J. Int. 121, 444- 458.

Nishimura, T., Nakamichi, H., Tanaka, S., Sato, M., Kobayashi, T., Ueki, S., Hamaguchi, H., Ohtake, M., Sato, H., 2000. Source process of very long-period seismic events associated with the 1998 activity of Iwate volcano, northeastern Japan. J. Geophys. Res. 105, 19135-19147.

Ohminato, T., Ereditato, D., 1998. Broadband seismic observations at Satsuma-Iwojima volcano, Japan. Geophys. Res. Lett. 24, 2845-2848.

Oikawa, J., Ida, Y., Yamaoka, K., Watanabe, H., Fukuyama, E., Sato, K., 1991. Ground deformation associated with volcanic tremor at Izu-Oshima volcano. Geophys. Res. Lett. 18, 443-446.

Power, J.A., Lahr, J.C., Page, R.A., Chouet, B.A., Stephens, C.D., Harlow, D.H., Murray, T.L., Davies, J.N., 1994. Seismic evolution of the 1989-90 eruption sequence of Redoubt volcano, Alaska. J. Volcanol. Geotherm. Res. 62, 69-94.

Richards, A.F., 1963. Volcanic sounds: investigations and analysis. J. Geophys. Res. 68, 919-928.

Ripepe, M., 1996. Evidence for gas influence on volcanic signals recorded at Stromboli. J. Volcanol. Geotherm. Res. 70, 221-233.

Ripepe, M., Poggi, P., Braun, T., Gordeev, E., 1996. Infrasonic waves and volcanic tremor at Stromboli. Geophys. Res. Lett. 23, 181-184.
Rowe, C.A., Aster, R.C., Kyle, P.R., Dibble, R.R., Schlue, J.W., 2000. Seismic and acoustic observations at Mt Erebus volcano, Ross Island, Antarctica, 1994-1998. J. Volcanol. Geotherm. Res. 101, 105-128.

Sammis, C., Julian, B.R., 1987. Fracture instabilities accompanying dike intrusion. J. Geophys. Res. 92, 2597-2605.

Sassa, K., 1936. Volcanic microtremors and eruption earthquakes. Mem. Coll. Sci. Univ. Kyoto Ser. A 18, 255-293.

Schick, R., 1992. Volcanic tremor: Seismic signals of (almost) unknown origin. In: Gasparini, P., Scarpa, R., Aki, K. (Eds.), Volcanic Seismology. IAVCEI Proc. Volcanol. 3, 157-167.

Schick, R., Lombardo, G., Patané, G., 1982. Volcanic tremors and shocks associated with eruptions at Etna (Sicily), September 1980. J. Volcanol. Geotherm. Res. 14, 261279.

Schlindwein, V., 1994. Spektralanalyse harmonischer Tremorsignale am Vulkan Semeru, Indonesien. Thesis. LudwigMaximilians Universität, Munich, $75 \mathrm{pp}$.

Schlindwein, V., Wasserman, J., Scherbaum, F., 1995. Spectral analysis of harmonic tremor signals from Mt. Semeru, Indonesia. Geophys. Res. Lett. 22, 1685-1688.

Scott, D.R., Stevenson, D.J., 1984. Magma solitons. Geophys. Res. Lett. 11, 1161-1164.

Scott, D.R., Stevenson, D.J., 1986. Magma ascent by porous flow. J. Geophys. Res. 91, 9283-9296.

Seidl, D., Schick, R., Riuscetti, M., 1981. Volcanic tremors at Etna: A model for hydraulic origin. J. Volcanol. Geotherm. Res. 44, 43-56.

Seidl, D., Kirbani, S.B., Brüstle, W., 1990. Maximum entropy spectral analysis of volcanic tremor using data from Etna (Sicily) and Merapi (central Java). Bull. Volcanol. 52, 460 474.

Shaw, H.R., Chouet, B., 1991. Fractal hierarchies of magma transport in Hawaii and critical self-organisation of tremor. J. Geophys. Res. 96, 10191-10207.

Sherburn, S., Scott, B.J., Nishi, Y., Suguhara, M., 1998. Seismicity at White Island volcano, New Zealand: a revised classification and inferences about source mechanism. J. Volcanol. Geotherm. Res. 83, 287-312.

Sherburn, S., Bryan, C.J., Hurst, A.W., Latter, J.H., Scott, B.J., 1999. Seismicity of Ruapehu volcano, New Zealand, 1971-1996: a review. J. Volcanol. Geotherm. Res. 88, 255278.

Shima, M., 1958. On the second volcanic micro-tremor at Aso volcano. Bull. Volcanol. Soc. J. 22, 1-6.

St Lawrence, W.F., Qamar, A., 1979. Hydraulic transients: A seismic source in volcanoes and glaciers. Science 203, 654 656.

Swanson, D.A., Duffield, W., Jackson, D., Peterson, D., 1979. Chronological narrative of the 1969-71 Mauna-Ulu eruption, Kilauea volcano, Hawaii. US Geol. Surv. Prof. Pap. 1056, 1-55.

Tsuruga, K., Yomogida, K., Honda, S., Ito, H., Ohminato, T., Kawakatsu, H., 1997. Spatial and temporal variations of volcanic earthquakes at Sakurajima volcano, Japan. J. Volcanol. Geotherm. Res. 75, 337-358. 
Ukawa, M., 1993. Excitation mechanism of large amplitude volcanic tremor associated with the 1989 Ito-Oki submarine volcano eruption. J. Volcanol. Geotherm. Res. 55, 33-50.

Ulrych, T.J., Bishop, T.N., 1975. Maximum entropy spectral analysis and autoregressive decomposition. Rev. Geophys. Space Phys. 13, 183-200.

Vila, J., Marti, J., Ortiz, R., Garcia, A., Correig, A.M., 1992. Volcanic tremors at Deception Island (south Shetland
Islands, Antarctica). J. Volcanol. Geotherm. Res. 53, 89102.

Wegler, U., Seidl, D., 1997. Kinematic parameters of the tremor wavefield at Mt. Etna (Sicily). Geophys. Res. Lett. 24, 759-762.

Yamaoka, K., Oikawa, J., Ida, Y., 1991. An isotropic source of volcanic tremor observations with a dense seismic network at Izu-Oshima volcano, Japan. J. Volcanol. Geotherm. Res. 47, 329-336. 